\title{
Nrf2 Activation Protects Mouse Beta Cells from Glucolipotoxicity by Restoring Mitochondrial Function and Physiological Redox Balance
}

\author{
Johanna Schultheis, ${ }^{1}$ Dirk Beckmann, ${ }^{1}$ Dennis Mulac, ${ }^{2}$ Lena Müller, ${ }^{3}$ Melanie Esselen, ${ }^{3}$ \\ and Martina Düfer $\mathbb{1}^{1}$ \\ ${ }^{1}$ University of Münster, Pharmaceutical and Medicinal Chemistry, Dept. of Pharmacology, Corrensstraße 48, \\ 48149 Münster, Germany \\ ${ }^{2}$ University of Münster, Pharmaceutical Technology and Biopharmacy, Corrensstraße 48, 48149 Münster, Germany \\ ${ }^{3}$ University of Münster, Institute of Food Chemistry, Corrensstraße 45, 48149 Münster, Germany
}

Correspondence should be addressed to Martina Düfer; martina.duefer@uni-muenster.de

Johanna Schultheis and Dirk Beckmann contributed equally to this work.

Received 13 May 2019; Revised 31 July 2019; Accepted 6 September 2019; Published 11 November 2019

Academic Editor: Ji C. Bihl

Copyright () 2019 Johanna Schultheis et al. This is an open access article distributed under the Creative Commons Attribution License, which permits unrestricted use, distribution, and reproduction in any medium, provided the original work is properly cited.

Influencing the redox balance of pancreatic beta cells could be a promising strategy for the treatment of diabetes. Nuclear factor erythroid 2p45-related factor 2 (Nrf2) is present in beta cells and regulates numerous genes involved in antioxidant defense. As reactive oxygen species (ROS) are important for beta cell signaling but induce oxidative stress when present in excess, this study elucidates the influence of Nrf2-activating compounds on different kinds of ROS and correlates changes in redox balance to effects on mitochondrial function, insulin release, and cell viability. Acute glucose stimulation ( $15 \mathrm{mmol} / \mathrm{L})$ of murine islet cells of C57Bl/6N mice affects ROS and redox status of the cells differently. Those ROS monitored by dihydroethidium, which detects superoxide radical anions, decrease. By contrast, oxidant status, monitored by dichlorodihydrofluorescein, as well as intracellular $\mathrm{H}_{2} \mathrm{O}_{2}$, increases. Glucolipotoxicity completely prevents these fast, glucose-mediated alterations and inhibits glucose-induced $\mathrm{NAD}(\mathrm{P}) \mathrm{H}$ production, mitochondrial hyperpolarization, and ATP synthesis. Oltipraz $(10 \mu \mathrm{mol} / \mathrm{L})$ or dimethyl fumarate (DMF, $50 \mu \mathrm{mol} / \mathrm{L}$ ) leads to nuclear accumulation of $\mathrm{Nrf} 2$, restores mitochondrial activity and glucose-dependent ROS turnover, and antagonizes glucolipotoxicity-induced inhibition of insulin release and apoptosis. Importantly, these beneficial effects only occur when beta cells are challenged and damaged by high lipid and carbohydrate supply. At physiological conditions, insulin release is markedly reduced in response to both Nrf2 activators. This is not associated with severe impairment of glucose-induced mitochondrial hyperpolarization or a rise in apoptosis but coincides with altered ROS handling. In conclusion, Nrf 2 activators protect beta cells against glucolipotoxicity by preserving mitochondrial function and redox balance. As our data show that this maintains glucose-stimulated insulin secretion, targeting Nrf2 might be suited to ameliorate progression of type 2 diabetes mellitus. By contrast, nonstressed beta cells do not benefit from Nrf2 activation, thus underlining the importance of physiological shifts in ROS homeostasis for the regulation of beta cell function.

\section{Introduction}

In early stages of type 2 diabetes mellitus, pancreatic beta cells try to compensate insulin resistance of fat, muscle, and liver by elevated hormone secretion. Thus, impaired glucose tolerance is accompanied by hyperinsulinemia. With the progression of diabetes, beta cells are severely damaged and finally fail to meet the increased demand. Consequently, therapeutic strategies making beta cells more resistant to cellular stress induced by continuing high carbohydrate and/or 
lipid intake, termed as glucolipotoxicity, are urgently needed. Since the discovery of the comparatively low level of antioxidant enzymes in pancreatic beta cells in the late 1990s [1], mechanisms to reinforce antioxidant defense pathways are objects of research. As activating individual pathways, e.g., solely catalase or superoxide dismutase, has turned out to be less effective [2,3], targeting antioxidant signaling mechanisms in a more general way may be more appropriate. Nuclear factor erythroid 2p45-related factor 2 (Nrf2) is a transcription factor that regulates the expression of several genes involved in redox metabolism [4-6]. Nuclear translocation of Nrf2 requires dissociation of its adaptor protein Keap1 in the cytosol. This is achieved by oxidants and electrophiles, e.g., via formation of covalent bonds with different cysteine residues of Keap1. Known Nrf2-activating compounds are dimethyl fumarate (DMF), oltipraz, sulforaphane, tert-butylhydroquinone, and dihydro-CDDO-trifluorethyl-amide.

Human and animal studies revealed that diabetes mellitus variably influences Nrf2-dependent pathways in different cell types: In renal biopsies of patients with diabetic nephropathy, elevation of oxidative stress markers coincided with nuclear accumulation of Nrf2 [7]. In retinal tissue of humans with diabetic retinopathy, Nrf2 mRNA and protein were elevated, but activation of target genes was reduced [8]. Nrf2 and its downstream signaling molecules were downregulated in the skin tissue of patients with diabetes [9] and in fibroblasts of diabetic rats exposed to oxidative stress [10]. Insulin resistance coincided with elevated levels of Keap1 and reduced amounts of antioxidant enzymes in adipose tissue in a high-fat diet mouse model [11]. Experiments with Zucker diabetic fatty rats showed that Nrf2 staining in beta cells rises soon after the start of a high-fat diet. While beta cell damage, apparent as a reduction in insulin-positive islet area, was mostly reversible after a short period of a high-fat diet, regenerative capacity disappeared after prolonged intake [12]. Altogether, this points not only to a tissue- and organdependent activation of Nrf2 but also to impairment of Nrf2 signaling in response to diabetes or malnutrition. Consequently, amongst other parameters involved in balancing oxidative stress, Nrf2 was suggested to serve as a biomarker to assess the risk profile for cardiovascular disease [13].

Insight into the therapeutic potential of Nrf2 for antidiabetic therapy is derived from experiments with animal models. $\mathrm{Db} / \mathrm{db}$ mice with genetic upregulation of Nrf2 activity via Keap1 knockdown were protected against the loss of glycemic control [14]. In line with this observation, treatment of mice on a high-fat diet with synthetic or natural Nrf2 activators reduced food intake and obesity [15] and ameliorated insulin resistance $[11,16]$. Protective effects were mainly ascribed to reduced lipogenesis and decreased glucose disposal $[11,15]$, but Nrf2 can also influence the endocrine pancreas (reviewed in [17]). It was demonstrated that Nrf2activating compounds increased the expression of antioxidant target genes [18-21]. Furthermore, a positive influence of Nrf2 activators on insulin secretion in response to an oral glucose tolerance test was reported for diabetic $\mathrm{db} / \mathrm{db}$ mice. This effect was accompanied by an elevation of an insulinpositive area in pancreatic sections [14]. Therefore, it was suggested that activators of $\mathrm{Nrf} 2$ could be used to counteract beta cell damage induced by overnutrition or inflammation [22]. So far, the in vivo data and subsequent analysis of islet histology provide evidence for the protection of the endocrine pancreas by Nrf2 activators applied during the development of type 2 diabetes mellitus. Of note, studies addressing beta cells and Nrf2 activators ex vivo are mainly limited to stress models with $\mathrm{H}_{2} \mathrm{O}_{2}$ and focus on the importance of Nrf2-regulated genes for beta cell death $[18,19,21]$. The direct influence of Nrf2-activating compounds on functional parameters, such as ATP production or insulin release in response to the pathophysiologically relevant challenge of beta cells by high glucose and lipid concentrations, remains to be elucidated.

Although pancreatic islets are susceptible to oxidative stress, reactive oxygen species (ROS) are not harmful per se but can serve as important signaling molecules in beta cells, if concentrations are not too high [23, 24]. Consequently, strategies targeting antioxidant capacity have to be analyzed carefully. Up to now, the effects of permanently elevated glucose and lipid concentrations on physiologically generated ROS (e.g., via mitochondrial metabolism) during acute stimulation of beta cells by nutrients have not been investigated in detail. Furthermore, the impact of Nrf2 on (patho)physiological changes in ROS in pancreatic islets is not known. The present study elucidates the changes in different kinds of ROS induced by glucolipotoxic cell stress in correlation with reduction equivalents, mitochondrial function, apoptosis, and insulin release. The susceptibility of these parameters to Nrf2-activating compounds was characterized in response to high glucose/lipid load as well as under standard conditions.

\section{Material and Methods}

2.1. Cell and Islet Preparation. Experiments were performed with islets of Langerhans from adult C57Bl/6N mice (Charles River, Sulzfeld, Germany). The principles of laboratory animal care were followed according to German laws. Mice were euthanized using $\mathrm{CO}_{2}$. Islets were isolated by collagenase digestion and cultured in RPMI 1640 medium $(11.1 \mathrm{mmol} / \mathrm{L}$ glucose) supplemented with $10 \%$ fetal calf serum, $100 \mathrm{U} / \mathrm{mL}$ penicillin, and $100 \mu \mathrm{g} / \mathrm{mL}$ streptomycin at $37^{\circ} \mathrm{C}$ in a $5 \%$ $\mathrm{CO}_{2}$ humidified atmosphere. After preparation, islets or dispersed islet cells were kept overnight in standard culture medium. In experiments with oltipraz or DMF, Nrf2 activators were added during the overnight culture period (1216h). Next day, medium was replaced by glucolipotoxic medium ( $25 \mathrm{mmol} / \mathrm{L}$ glucose and $100 \mu \mathrm{mol} / \mathrm{L}$ palmitate) or the respective control medium for $30 \mathrm{~min}$ up to $48 \mathrm{~h}$ as indicated in the figures (Nrf2 activators still present). For the investigation of apoptosis induced by T0901317 $(10 \mu \mathrm{mol} / \mathrm{L})$, glucose concentration amounted to $33 \mathrm{mmol} / \mathrm{L}$ and islet cells were cultured in this medium with or without oltipraz for $48 \mathrm{~h}$ or seven days.

2.2. Solutions and Chemicals. Insulin secretion was determined in a bath solution of (mmol/L) $122 \mathrm{NaCl}, 4.7 \mathrm{KCl}$, $1.1 \mathrm{MgCl}_{2}, 2.5 \mathrm{CaCl}_{2}$, and 10 HEPES (pH 7.4). All other 
parameters were measured at $37^{\circ} \mathrm{C}$ in a solution containing (mmol/L) $140 \mathrm{NaCl}, 5 \mathrm{KCl}, 1.2 \mathrm{MgCl}_{2}, 2.5 \mathrm{CaCl}_{2}$, and 10 HEPES (pH 7.4). Glucose was added as indicated. For glucolipotoxic medium, palmitate was dissolved in $0.1 \mathrm{~N} \mathrm{NaOH}$ and further diluted in double-distilled water containing $0.56 \%$ fat-free bovine serum albumin. This solution was added to the culture medium in a proportion of $1: 10$ to obtain a final palmitate concentration of $100 \mu \mathrm{mol} / \mathrm{L}$. Control medium contained the respective amount of fat-free bovine serum albumin.

Collagenase $\mathrm{P}$ was obtained from Roche Diagnostics (Mannheim, Germany), and RPMI 1640, fetal calf serum, and penicillin/streptomycin were obtained from Life Technologies (Darmstadt, Germany). Rat insulin and dihydroethidium were ordered from Biotrend (Köln, Germany), and BES- $\mathrm{H}_{2} \mathrm{O}_{2}$ was from Wako Chemicals (Neuss, Germany). Protease inhibitor cocktail was from Roth (Karlsruhe, Germany). Antibodies were obtained from Abcam (Cambridge, UK) or Santa Cruz (Heidelberg, Germany). All other chemicals were purchased from Sigma-Aldrich (Taufkirchen, Germany) or Diagonal (Münster, Germany).

2.3. Insulin Secretion. After culture of the islets for 2 or $48 \mathrm{~h}$ under control or glucolipotoxic conditions with or without Nrf2-activating drugs, islets were silenced by incubation in bath solution with $5.6(2 \mathrm{~h})$ and $3(1 \mathrm{~h}) \mathrm{mmol} / \mathrm{L}$ glucose. Nrf2 activators were not present in the $1 \mathrm{~h}$ period and in the following secretion experiment. For the determination of insulin release, batches of five islets were incubated at $37^{\circ} \mathrm{C}$ for $60 \mathrm{~min}$ with the indicated glucose concentrations. Secretion was stopped by fast cooling, and insulin concentration was quantified by radioimmunoassay using rat insulin as the standard.

2.4. Determination of ROS and Redox Status. Glucoseinduced alterations in redox signaling in response to acute stimulation were determined by incubating islet cells in bath solution with $0.5,3$, or $15 \mathrm{mmol} / \mathrm{L}$ glucose at $37^{\circ} \mathrm{C}$ for $1 \mathrm{~h}$. $2^{\prime}, 7^{\prime}$-Dichlorodihydrofluorescein-diacetate (DCDHF-DA, $20 \mu \mathrm{mol} / \mathrm{L}), 3^{\prime}$-O-acetyl-6'-O-pentafluorobenzenesulfonyl$2^{\prime}-7^{\prime}$-difluorofluorescein-acetate (BES- $\mathrm{H}_{2} \mathrm{O}_{2}-\mathrm{Ac}, 5 \mu \mathrm{mol} / \mathrm{L}$ ), or dihydroethidium (DHE, $1 \mu \mathrm{mol} / \mathrm{L}$ ) was added for the last $15 \mathrm{~min}$ of the $1 \mathrm{~h}$ period.

To detect the accumulation of $\mathrm{H}_{2} \mathrm{O}_{2}$, superoxide anion radicals, or altered redox status in response to different culture conditions, medium was removed after the respective culture period and cells were loaded with fluorescence dye in bath solution with $15 \mathrm{mmol} / \mathrm{L}$ glucose at $37^{\circ} \mathrm{C}$ for $15 \mathrm{~min}$ (DCDHF, DHE) or with $10 \mathrm{mmol} / \mathrm{L}$ glucose for $60 \mathrm{~min}$ $\left(\mathrm{BES}-\mathrm{H}_{2} \mathrm{O}_{2}\right)$. Fluorescence was excited at $480 \mathrm{~nm}$, and emission was measured by a digital camera (filter $515 \mathrm{~nm}$ ).

2.5. Determination of Mitochondrial Membrane Potential $\left(\Delta \Psi_{m}\right)$ and $N A D(P) H$. For the determination of $\Delta \Psi_{\mathrm{m}}$, cells were incubated in bath solution with 0.5 or $15 \mathrm{mmol} / \mathrm{L}$ glucose for $1 \mathrm{~h}$ and loaded with rhodamine $123(26 \mu \mathrm{mol} / \mathrm{L}$, $37^{\circ} \mathrm{C}$ ) in the last $15 \mathrm{~min}$. Fluorescence was normalized to maximal depolarization obtained with $\mathrm{NaN}_{3}(10 \mathrm{mmol} / \mathrm{L})$ in each experiment. A lower percentage value indicates a more hyperpolarized status. To detect NAD $(\mathrm{P}) \mathrm{H}$ autofluorescence, cells were incubated in bath solution with $0.5 \mathrm{mmol} / \mathrm{L}$ glucose for $1 \mathrm{~h}$. Changes in $\mathrm{NAD}(\mathrm{P}) \mathrm{H}$ were determined after stimulation with $15 \mathrm{mmol} / \mathrm{L}$ glucose (compared to $0.5 \mathrm{mmol} / \mathrm{L}$ glucose). Excitation was achieved at $480 \mathrm{~nm}\left(\Delta \Psi_{\mathrm{m}}\right)$ or $360 \mathrm{~nm}(\mathrm{NAD}(\mathrm{P}) \mathrm{H})$, and emission was measured as described above.

2.6. Determination of ATP Content. After being cultured under control or glucolipotoxic conditions in the presence or absence of oltipraz for $48 \mathrm{~h}$, islets were silenced in bath solution containing $6 \mathrm{mmol} / \mathrm{L}$ glucose for $1 \mathrm{~h}$. Subsequently, 20 islets per batch were incubated in bath solution with either 0.5 or $15 \mathrm{mmol} / \mathrm{L}$ glucose at $37^{\circ} \mathrm{C}$ for $30 \mathrm{~min}$. Islets were lysed and incubated at $60^{\circ} \mathrm{C}$ to inactivate enzymes for $20 \mathrm{~min}$. ATP content was measured using a luciferin/luciferase-based assay according to the manufacturer's protocol (ATP determination kit, Invitrogen ${ }^{\mathrm{TM}}$, Thermo Fisher Scientific).

2.7. Apoptotic Cell Death. According to the manufacturer's protocol (in situ cell death detection kit, fluorescein, Roche Diagnostics), cells were washed with phosphate-buffered saline and fixed with $3 \%$ paraformaldehyde. Cells were permeabilized on ice for $2 \mathrm{~min}(0.1 \%$ Triton-X) and washed again. Each sample was treated with TUNEL reaction mixture and incubated in a humidified atmosphere for $1 \mathrm{~h}$. Thereafter, cells were washed, nuclei were stained with bisbenzimide (Hoechst-33258), and fluorescence of apoptotic cells was excited at $480 \mathrm{~nm}$. Nuclear staining was excited at $380 \mathrm{~nm}$.

2.8. Nrf2 Immunofluorescence Staining. After treatment as indicated, cells were fixed in paraformaldehyde $(3 \%, 1 \mathrm{~h}$, room temperature) and permeabilized by Triton-X/sodium dodecyl sulfate $(0.25 \% / 1 \%, 10 \mathrm{~min})$. To reduce nonspecific binding, normal goat serum blocking solution was used (30 min). Cells were incubated with anti-Nrf2 primary antibody (Abcam, ab62352, $1: 200$ ) in the dark at $37^{\circ} \mathrm{C}$ for $10 \mathrm{~h}$. Thereafter, cells were washed 5 times with phosphate buffer. Alexa Fluor $488^{\circledR}$-coupled secondary antibody was added (ab150077, 1:1000) for $1 \mathrm{~h}$. Finally, cells were embedded in mounting medium containing $4^{\prime}, 6$-diamidine- $2^{\prime}$-phenylindole (Fluoroshield ${ }^{\circledR}$ with DAPI).

2.9. Western Blot Analysis. Approximately 400 islets per condition were lysed with RIPA buffer (mmol/L): 65 TRIS, 150 $\mathrm{NaCl}, 0.9$ EDTA, and 1\% Nonidet-P40 (10\%), containing $1 \%$ protease inhibitor cocktail (freshly added) and $0.1 \%$ dithiothreitol. Samples were homogenized by an ultrasonic homogenizer (SonoPuls GM mini20, BANDELIN) for $30 \mathrm{~s}$, and protein content was determined by a Bradford assay. Samples were diluted to a standardized protein concentration. Proteins were separated on a $10 \%$ polyacrylamide gel and blotted on a nitrocellulose membrane (Amersham ${ }^{\text {TM }}$ $\operatorname{Protan}^{\circledR}$, VWR, Germany), followed by incubation with anti-Nrf2 primary antibody (Abcam, ab62352, 1:1000) at $4^{\circ} \mathrm{C}$ up to $48 \mathrm{~h}$. PCNA protein was used as the loading control (Santa Cruz, sc-25280 1:500). The secondary antibody (Cell Signaling Technology, anti-rabbit, No. 7074 1:1000) was 
added at room temperature for $1 \mathrm{~h}$. All antibody dilutions were done with buffer containing 5\% nonfat dry milk. Chemiluminescence (WesternBright $^{\mathrm{TM}}$ Sirius $^{\mathrm{TM}}$, Advansta Inc.) was detected with CemiDoc ${ }^{\mathrm{TM}}$ XRS (Bio-Rad).

2.10. Data Evaluation and Statistical Analysis. Data were collected from islets or islet cells of at least three independent mouse preparations for each series of experiments. Values are given as the means \pm SEM. For the evaluation of $\Delta \Psi_{\mathrm{m}}$, six consecutive data points (10 s intervals) directly before the addition of $\mathrm{NaN}_{3}$ were averaged and normalized to maximal depolarization. For the analysis of $\mathrm{NAD}(\mathrm{P}) \mathrm{H}$, all those cells displaying a reversible reaction in response to $15 \mathrm{mmol} / \mathrm{L}$ glucose were included and the difference in response to $15 v s .0 .5 \mathrm{mmol} / \mathrm{L}$ glucose was calculated (6 consecutive data points, $3 \mathrm{~s}$ intervals). Apoptosis was determined by counting the number of TUNEL-positive cells in relation to all cells in 10 randomly selected fields of each sample. Confocal images were taken by an iMIC digital microscope 2.0 (FEI, Munich, Germany) or with a IX81 fluorescence microscope (Olympus, Hamburg, Germany) with the following filter systems (DAPI/Alexa Fluor $488^{\circledR}$ ): excitation at 360 $370 \mathrm{~nm} / 460-500 \mathrm{~nm}$, dichroic mirror at $400 \mathrm{~nm} / 505 \mathrm{~nm}$, and emission at $426-446 \mathrm{~nm} / 510-560 \mathrm{~nm}$. Images were taken as multilayer stacks with a minimum of 12 images. Out of focus, fluorescence was reduced by deconvolution (Wiener filter, cellSens Dimension Software 1.17). Western blot band intensities were analyzed with Image Lab 5.0 Software (BioRad). Statistical significance was assessed by Student's $t$-test or by ANOVA followed by Student-Newman-Keuls post hoc test for multiple comparisons. Values of $p \leq 0.05$ were considered significant.

\section{Results}

3.1. Glucolipotoxicity Reduces Insulin Secretion and Influences Acute Effects of Glucose on Redox Homeostasis. Redox status and ROS play a crucial role in beta cell physiology and in the process of beta cell exhaustion by excessive nutrient supply. Acute stimulation of murine beta cells by $15 \mathrm{mmol} / \mathrm{L}$ glucose for $1 \mathrm{~h}$ induced alterations in cellular redox balance compared to beta cells treated with $0.5 \mathrm{mmol} / \mathrm{L}$ glucose for $1 \mathrm{~h}$. ROS determined by DHE oxidation to ethidium and 2-hydroxyethidium (summarized as " $\mathrm{DHE}_{\mathrm{ox}}$ ") in the presence of the stimulatory glucose concentration were lower compared to the substimulatory glucose concentration (Figure 1(a) point "0", continuous vs. dotted line). Amongst others, this indicates a decrease in accumulation of superoxide radical anions. By contrast, oxidation of DCDHF to $2^{\prime}, 7^{\prime}$-dichlorofluorescein (DCF) increased in response to a 1-hour stimulation with $15 \mathrm{mmol} / \mathrm{L} v$ s. $0.5 \mathrm{mmol} / \mathrm{L}$ glucose (Figure 1(b) point " 0 ", continuous $v s$. dotted line). With $3 \mathrm{mmol} / \mathrm{L}$ glucose, which is the substimulatory concentration routinely used to determine basal insulin secretion, the degree of $\mathrm{DHE}_{\mathrm{ox}}$ and DCF was similar to $0.5 \mathrm{mmol} / \mathrm{L}$ glucose (Suppl. Fig. 1). To test whether acute glucose stimulation leads to $\mathrm{H}_{2} \mathrm{O}_{2}$ accumulation, the fluorescence dye BES- $\mathrm{H}_{2} \mathrm{O}_{2}$ [25] was used. Figure 1(c) (point "0") illustrates that fluorescence is higher in response to $1 \mathrm{~h}$ stimulation with $15 \mathrm{mmol} / \mathrm{L}$ compared to $0.5 \mathrm{mmol} / \mathrm{L}$ glucose. The decrease in the fluorescence of the oxidation products of DHE with concomitant increase in $\mathrm{BES}-\mathrm{H}_{2} \mathrm{O}_{2}$ fluorescence might indicate elevated formation of $\mathrm{H}_{2} \mathrm{O}_{2}$ by dismutation of superoxide radical anions.

$\mathrm{H}_{2} \mathrm{O}_{2}$ was suggested to contribute to acute, physiological regulation of insulin secretion [24]. To test for any influence of glucolipotoxicity on the physiological glucose-induced shifts in redox homeostasis described above, changes in redox balance and insulin release were determined after short- and long-term culture in medium supplemented with $25 \mathrm{mmol} / \mathrm{L}$ glucose and $100 \mu \mathrm{mol} / \mathrm{L}$ palmitate. Glucolipotoxic conditions were without any negative effect on insulin release after a short period of $2 \mathrm{~h}$ but, as expected, significantly reduced glucose-stimulated insulin release after $48 \mathrm{~h}$ (Figure 1(d)). Correspondingly, the difference in DCF or $\mathrm{DHE}_{\text {ox }}$ fluorescence in response to the two glucose concentrations declined with increased duration of glucolipotoxic culture. It completely disappeared when cells were stimulated with 0.5 or $15 \mathrm{mmol} / \mathrm{L}$ glucose subsequent to the $48 \mathrm{~h}$ culture under glucolipotoxic conditions (Figures $1(\mathrm{a})$ and $1(\mathrm{~b})$, point " $48 \mathrm{~h}$ "). With respect to fluorescence of BES- $\mathrm{H}_{2} \mathrm{O}_{2}$, glucosemediated changes even reversed, i.e., acute stimulation with 15 vs. $0.5 \mathrm{mmol} / \mathrm{L}$ glucose, resulted in a significantly reduced level instead of an increased level of $\mathrm{H}_{2} \mathrm{O}_{2}$ after glucolipotoxic culture for $48 \mathrm{~h}$ (Figure 1(c)).

\subsection{Long-Term Treatment with Glucolipotoxicity Shifts the} Redox Status in Beta Cells. To investigate the influence of glucolipotoxicity on intracellular ROS accumulation per se, beta cells were cultured as described above. Thereafter, DCF, BES$\mathrm{H}_{2} \mathrm{O}_{2}$, and $\mathrm{DHE}_{\mathrm{ox}}$ fluorescence were determined without any further acute treatment with 0.5 or $15 \mathrm{mmol} / \mathrm{L}$ glucose. Compared to control conditions, all indicators showed reduced fluorescence in response to the $48 \mathrm{~h}$ culture period in glucolipotoxic medium (Figures $2(\mathrm{a})-2(\mathrm{c})$ ). This unexpected shift in redox balance to a less oxidized status might be a consequence of activation of antioxidant defense pathways during the $48 \mathrm{~h}$ culture period. The kinetics of changes in DCF fluorescence illustrated in Figure 2(a) show a tendency to increased DCF fluorescence during the first $2 \mathrm{~h}$ in glucolipotoxic medium, but this did not reach statistical significance. After $48 \mathrm{~h}$, DCF fluorescence was decreased compared to the starting point (absolute values, control: $1557 \pm 198$ a.u., $n=144$ cells, vs. $48 \mathrm{~h}$ glucolipotoxicity: $688 \pm 43$ a.u., $n=$ 150 cells, $p \leq 0.001)$. To exclude that these results are restricted to one special culture condition, another model for glucolipotoxicity was used. In this setup, the liver X receptor agonist T0901317 $(10 \mu \mathrm{mol} / \mathrm{L})$, which activates cellular lipid synthesis, was combined with $33 \mathrm{mmol} / \mathrm{L}$ glucose. In agreement with our other results, the treatment of beta cells with these glucolipotoxic conditions for $48 \mathrm{~h}$ also resulted in a less oxidized redox status (DCF fluorescence: decreased to $78.5 \pm 3.9 \%$ of the initial value, $n=3$ independent preparations, $p \leq 0.05$; $^{2} E_{\text {ox }}$ fluorescence: decrease from $40 \pm 2$ to $29 \pm 2$ a.u., $n=89$ and 92 cells, respectively, $p \leq 0.001$ ).

3.3. Influence of Nrf2 Activation in Nonstressed Beta Cells. Nrf2 is known as an important regulator for antioxidant 

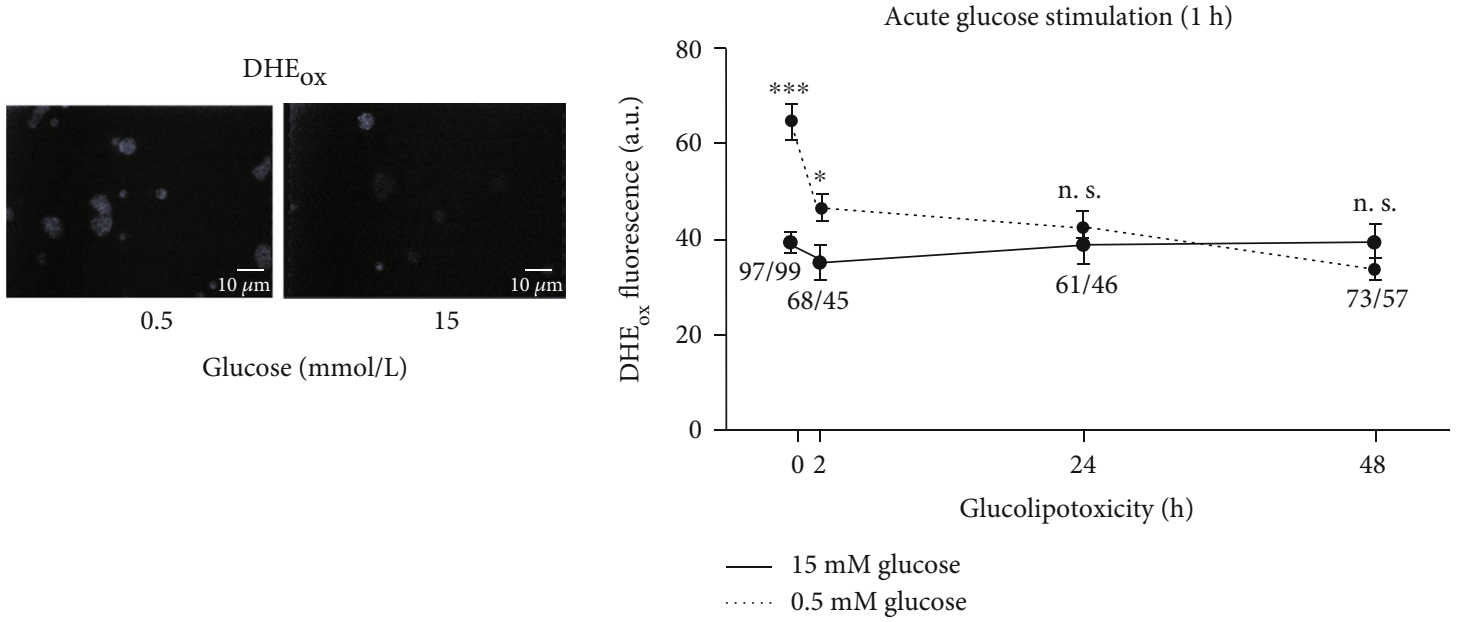

(a)
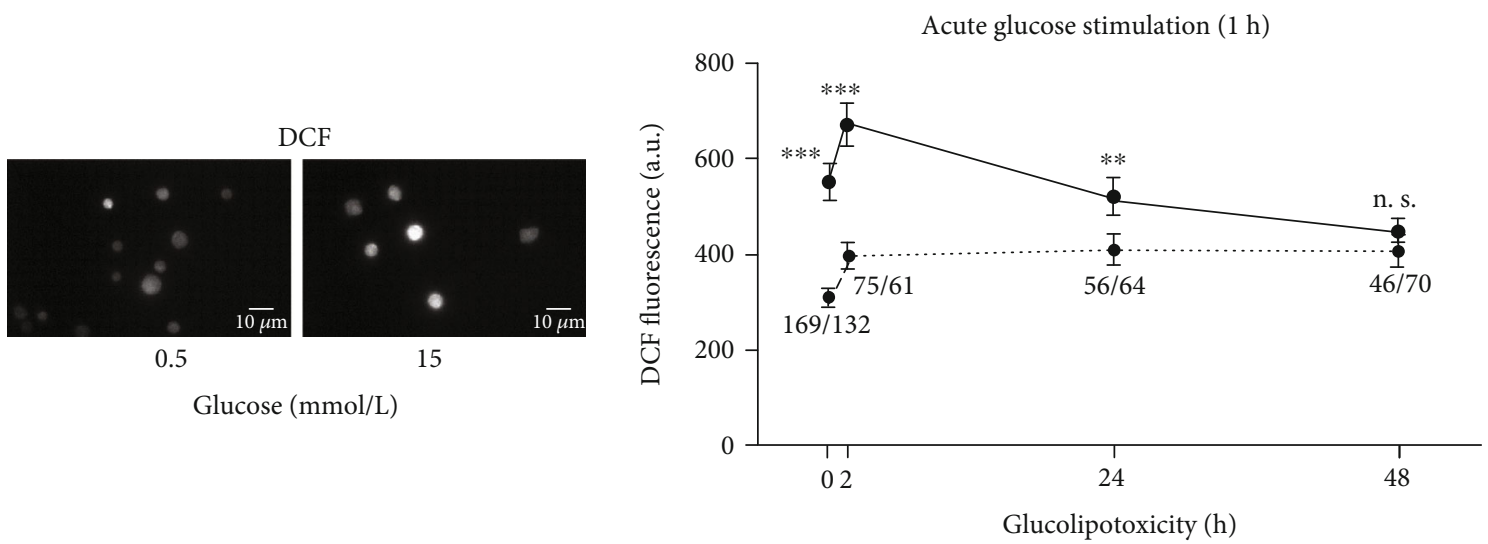

DCF

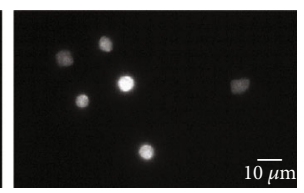

15

Glucose ( $\mathrm{mmol} / \mathrm{L})$

Glucolipotoxicity (h)

$15 \mathrm{mM}$ glucose

$0.5 \mathrm{mM}$ glucose

(b)

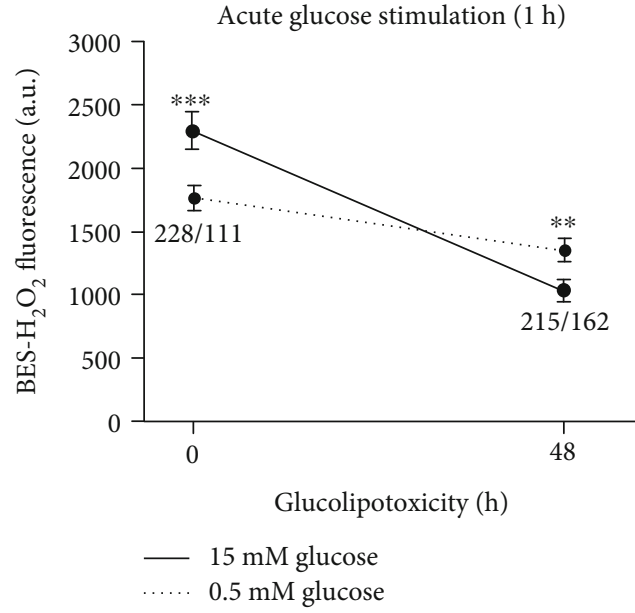

(c)

Figure 1: Continued. 


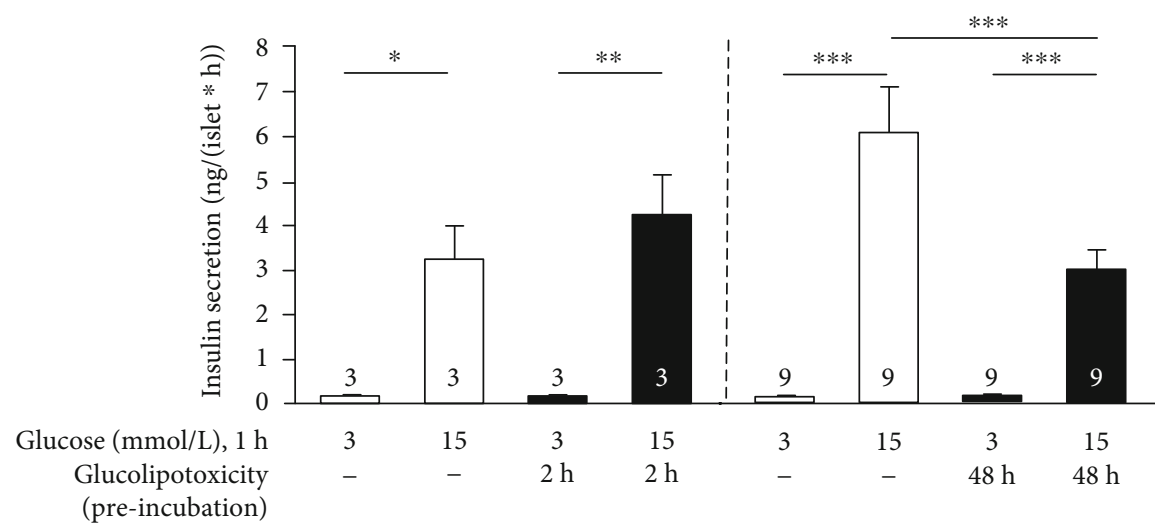

(d)

FIGURE 1: Glucolipotoxicity impairs insulin release and alters acute, glucose-induced changes in redox balance. (a-c) Mouse islet cells were cultured in control medium $(10 \mathrm{mmol} / \mathrm{L}$ glucose $)$ or in glucolipotoxic culture medium $(100 \mu \mathrm{mol} / \mathrm{L}$ palmitate and $25 \mathrm{mmol} / \mathrm{L}$ glucose $)$ for up to $48 \mathrm{~h}$. Thereafter, they were stimulated with bath solution supplemented with either 0.5 or $15 \mathrm{mmol} / \mathrm{L}$ glucose for $1 \mathrm{~h}$ and changes in fluorescence of $\mathrm{DHE}_{\text {ox }}((\mathrm{a})$, indicative of superoxide anion formation), DCF ((b), indicative of a more oxidized redox status), and BES- $\mathrm{H}_{2} \mathrm{O}_{2}\left((\mathrm{c})\right.$, indicative of $\mathrm{H}_{2} \mathrm{O}_{2}$ accumulation) were determined. (d) Insulin release of murine islets was measured in response to 3 and $15 \mathrm{mmol} / \mathrm{L}$ glucose ( $1 \mathrm{~h}$ steady-state incubation) after 2 or $48 \mathrm{~h}$ in culture medium with $100 \mu \mathrm{mol} / \mathrm{L}$ palmitate and $25 \mathrm{mmol} / \mathrm{L}$ glucose $v s$. control $(10 \mathrm{mmol} / \mathrm{L}$ glucose). In (a) and (b), representative images are shown on the left. Numbers in the graph indicate the number of islet cells $((\mathrm{a}-\mathrm{c}): 0,5 / 15 \mathrm{mmol} / \mathrm{L}$ glucose $)$ or independent preparations $(\mathrm{d}) .{ }^{*} p \leq 0.05,{ }^{* *} p \leq 0.01$, and ${ }^{* * *} p \leq 0.001 ; 15 v s .0 .5$ or $3 \mathrm{mmol} / \mathrm{L}$ glucose, $\mathrm{n}$. s.: not significant.

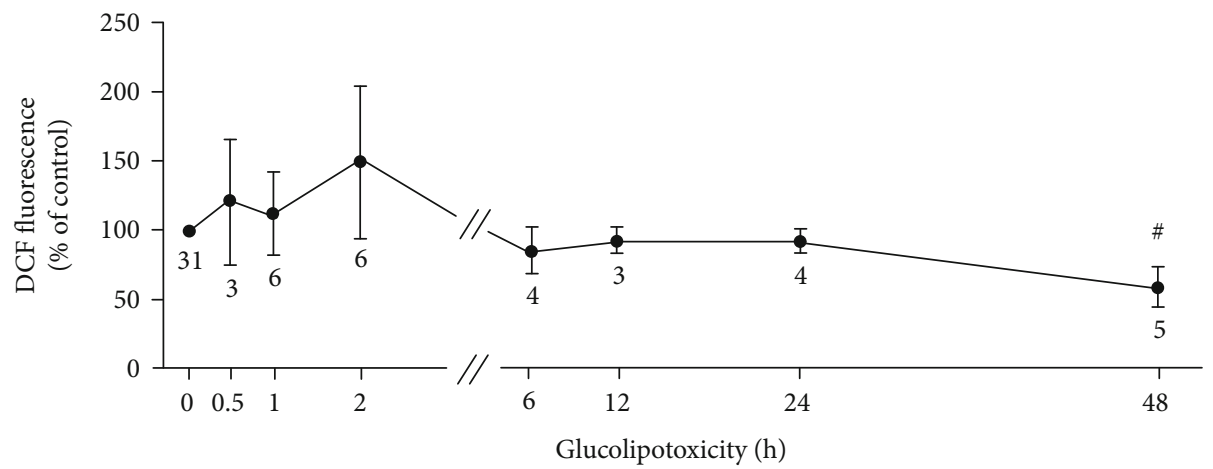

(a)

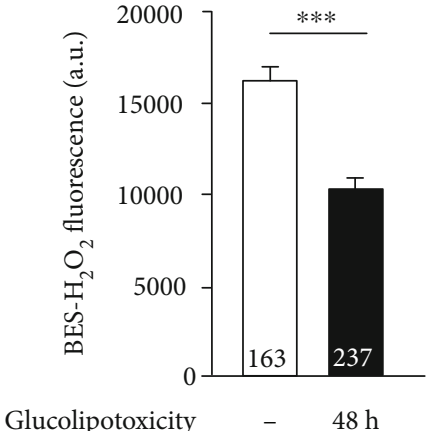

(b)

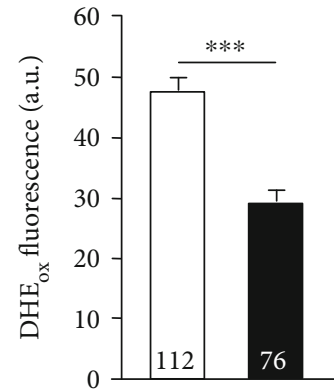

Glucolipotoxicity $\quad-\quad 48 \mathrm{~h}$

(c)

FIGURE 2: Culturing beta cells under glucolipotoxic conditions decreases the intracellular level of oxidation. Mouse islet cells were incubated in medium supplemented with $100 \mu \mathrm{mol} / \mathrm{L}$ palmitate and $25 \mathrm{mmol} / \mathrm{L}$ glucose $v s$. standard condition $(10 \mathrm{mmol} / \mathrm{L}$ glucose) for different time

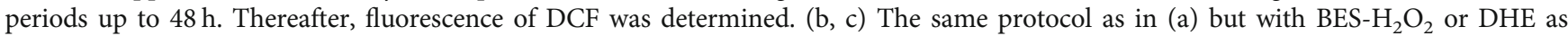
fluorescent dyes. Numbers in the graph denote the number of independent preparations (a), and numbers in bars indicate the number of islet cells (b, c). ${ }^{\#} p \leq 0.05 v$ s. standard condition (time point “ 0 "); ${ }^{* * *} p \leq 0.001$. 


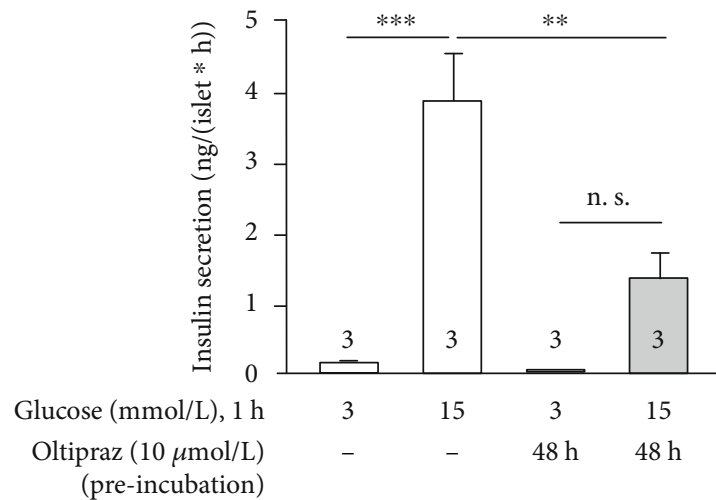

(a) Acute glucose stimulation

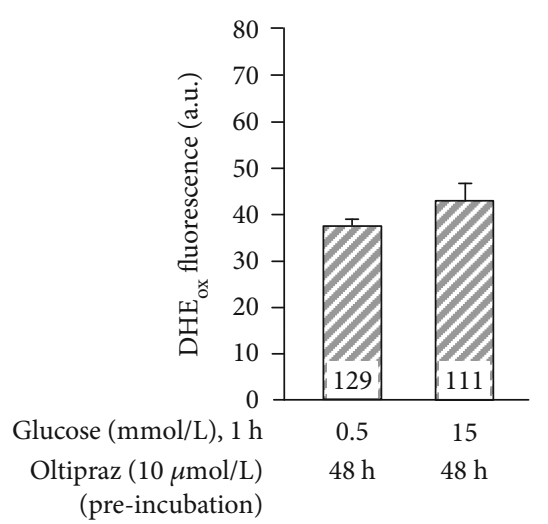

(c)

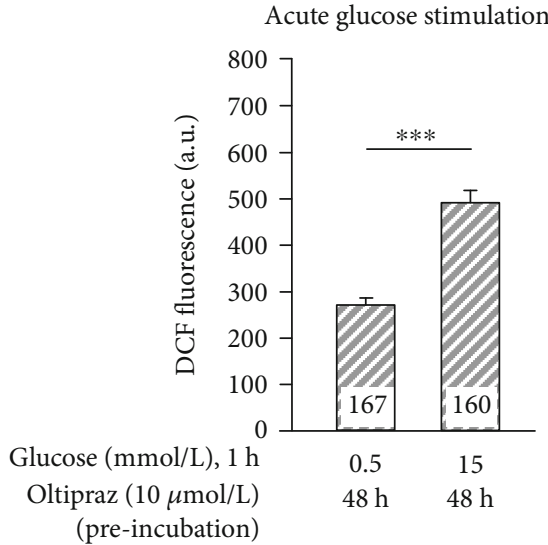

(d)

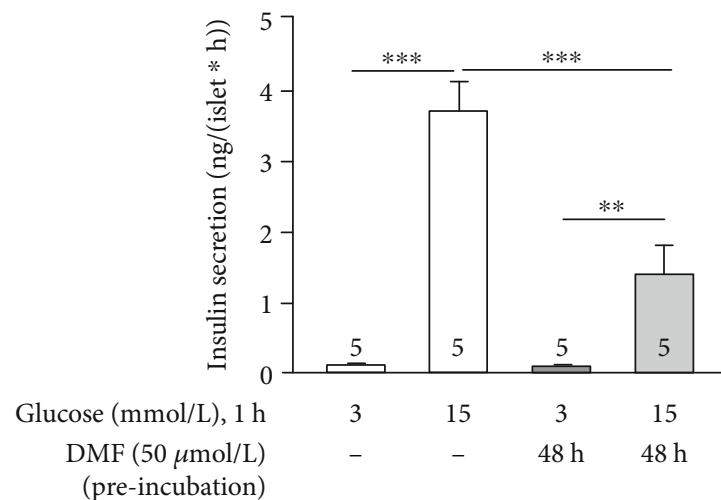

(b)

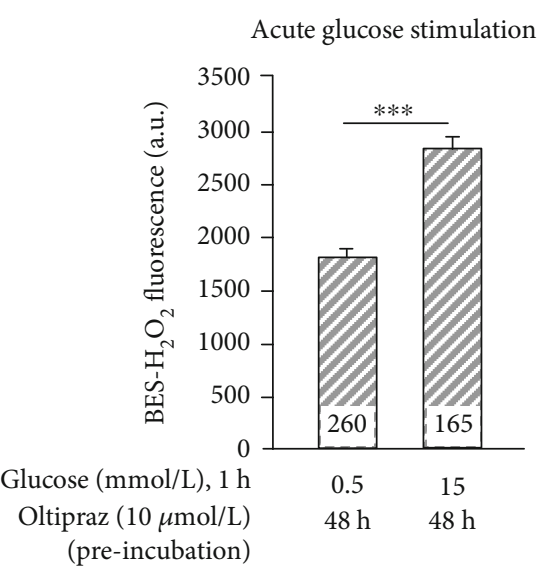

(e)

Figure 3: At physiological conditions, activation of Nrf2 inhibits insulin secretion and changes the glucose-dependent fast alterations in cellular ROS. ( $\mathrm{a}, \mathrm{b})$ Murine islets were cultured in standard medium in the absence (white bars) or presence (grey bars) of oltipraz $(10 \mu \mathrm{mol} / \mathrm{L})$ or DMF $(50 \mu \mathrm{mol} / \mathrm{L})$ for $48 \mathrm{~h}$. Thereafter, islets were stimulated with 3 or $15 \mathrm{mmol} / \mathrm{L}$ glucose for $1 \mathrm{~h}$ and insulin release was measured. (c-e) The same procedure as described for $(\mathrm{a}, \mathrm{b})$ but with dispersed islet cells. Acute $1 \mathrm{~h}$ stimulation with $15 \mathrm{mmol} / \mathrm{L}$ glucose did not reduce DHE-sensitive ROS compared to $0.5 \mathrm{mmol} / \mathrm{L}$ glucose (c) but still elevated DCF and BES- $\mathrm{H}_{2} \mathrm{O}_{2}$ fluorescence (d, e). Numbers in bars indicate the number of independent preparations $(\mathrm{a}, \mathrm{b})$ or cells $(\mathrm{c}-\mathrm{e}) .{ }^{* *} p \leq 0.01$ and ${ }^{* * *} p \leq 0.001$; n. s.: not significant.

defense pathways. To unravel whether activation of Nrf2 protects against glucolipotoxicity by restoring the physiological glucose-mediated changes in ROS balance, two Nrf2 activators, oltipraz and dimethyl fumarate (DMF), were used. First, the influence of both compounds on islets cultured in standard conditions was tested. $48 \mathrm{~h}$ culture of mouse islets with oltipraz $(10 \mu \mathrm{mol} / \mathrm{L})$ or DMF $(50 \mu \mathrm{mol} / \mathrm{L})$ did not affect basal insulin secretion ( $3 \mathrm{mmol} / \mathrm{L}$ glucose) but dramatically reduced insulin release in response to $15 \mathrm{mmol} / \mathrm{L}$ glucose to approximately $35-40 \%$ compared to controls (Figures 3(a) and 3(b)). As the influence of Nrf2 activation on insulin release under physiological conditions was clearly negative, we tested for any effects on glucose-mediated changes in beta cell ROS. Contrasting to the effects illustrated in Figure 1(a), $\mathrm{DHE}_{\mathrm{ox}}$ fluorescence did not differ in response to stimulation with 15 vs. $0.5 \mathrm{mmol} / \mathrm{L}$ glucose after treatment of beta cells with oltipraz for $48 \mathrm{~h}$ (Figure 3(c)). The physiological rise in DCF fluorescence that was observed by acutely stimulating beta cells with $15 \mathrm{mmol} / \mathrm{L}$ compared to $0.5 \mathrm{mmol} / \mathrm{L}$ glucose was still present but lower $(483 \pm 22$ a.u., $\mathrm{n}=160$, vs. $567 \pm 34$ a.u., $n=132, p \leq 0.01$ ) after $48 \mathrm{~h}$ culture of beta cells with medium supplemented with oltipraz (Figure 3(d), compared to the point of origin of the continuous line in Figure 1(b)). This indicates a less oxidized status of the beta cells in response to glucose after treatment with oltipraz. However, with respect to $\mathrm{H}_{2} \mathrm{O}_{2}$, acute stimulation with $15 \mathrm{mmol} / \mathrm{L}$ glucose increased fluorescence of BES- $\mathrm{H}_{2} \mathrm{O}_{2}$ significantly more in beta cells pretreated with oltipraz compared to control (right bar in Figure 3(e)vs. point of origin of the continuous line in Figure 1(c): $2781 \pm 100$ a.u., $n=$ $165, v s .2291 \pm 128$ a.u., $n=111, p \leq 0.001)$.

3.4. Restoration of the Glucose-Dependent Changes in Redox Balance by Nrf2 Activation during Glucolipotoxic Culture. The data described above showed that activation of Nrf2 under physiological conditions inhibited insulin release and altered the redox profile in response to acute glucose stimulation. Next, we checked whether activation of Nrf2 could protect against glucolipotoxic effects. In these experiments, oltipraz $(10 \mu \mathrm{mol} / \mathrm{L})$ or DMF $(50 \mu \mathrm{mol} / \mathrm{L})$ was added before $(12-16 \mathrm{~h})$ and during glucolipotoxic culture $(48 \mathrm{~h})$. Both Nrf2 activators protected against inhibition of insulin release 
by glucolipotoxicity (Figures 4(a) and 4(b)). Coincubation of islet cells with oltipraz $(10 \mu \mathrm{mol} / \mathrm{L})$ largely restored the physiological glucose-induced shifts in the redox profile, i.e., an increase in DCF fluorescence and elevated oxidation of BES- $\mathrm{H}_{2} \mathrm{O}_{2}$ as well as a decrease in $\mathrm{DHE}_{\text {ox }}$ fluorescence in response to 1 -h stimulation with $15 \mathrm{mmol} / \mathrm{L}$ vs. $0.5 \mathrm{mmol} / \mathrm{L}$ glucose (Figures 4(c)-4(e), compared to Figures 1(a)-1(c)). By contrast, ROS accumulation directly after $48 \mathrm{~h}$ of glucolipotoxicity was not affected (Figures $4(\mathrm{f})-4(\mathrm{~h})$ ).

Alterations in intracellular Nrf2 localization were monitored under the same conditions. After control or glucolipotoxic culture for $48 \mathrm{~h}, \mathrm{Nrf2}$ staining was weak and mainly cytosolic, appearing diffused or dot-like (Figure 5(a), upper traces). Nuclear Nrf2 staining clearly increased when oltipraz or DMF was present during glucolipotoxic culture (Figure 5(a), lower traces). Western blot analysis was performed to elucidate whether Nrf2 protein expression was increased by $\mathrm{Nrf} 2$ activating compounds. The data presented in Figure 5(b) illustrate that Nrf2 protein tends to increase in islets exposed to glucolipotoxic medium and oltipraz but the effect was not statistically different.

\subsection{Protection against Impairment of Mitochondrial Function} by Nrf2 Activation. Our data show that glucolipotoxicity prevents the physiological alterations of ROS induced by acute stimulation with glucose. Activation of Nrf2 by oltipraz protects against this. In general, intracellular ROS can be produced by various mechanisms, e.g., via NADPH-dependent oxidases or mitochondrial respiration [26,27]. As mitochondrial metabolism is an important source for superoxide radical and subsequent $\mathrm{H}_{2} \mathrm{O}_{2}$ generation in response to acute glucose stimulation in pancreatic beta cells, it was investigated if restoration of the physiological redox profile by oltipraz results from protective effects on mitochondrial function. To test for this, ATP content, NAD(P)H autofluorescence, and mitochondrial membrane potential were determined after glucolipotoxic cell culture $(48 \mathrm{~h})$. ATP content increases in response to $15 \mathrm{mmol} / \mathrm{L}$ vs. $0.5 \mathrm{mmol} / \mathrm{L}$ glucose. Glucose-mediated elevation of ATP production was markedly decreased after glucolipotoxic culture. Islets were protected by coculture with oltipraz (Figure 6(a)). In agreement with impaired ATP synthesis, the increase in $\mathrm{NAD}(\mathrm{P}) \mathrm{H}$ autofluorescence (Figure 6(b), exemplary trace) induced by elevating glucose concentration from 0.5 to $15 \mathrm{mmol} / \mathrm{L}$ was distinctly reduced after glucolipotoxic culture (Figure 6(b), black bar vs. white bar). This was prevented by coincubation with oltipraz (Figure 6(b), hatched bar). Stimulating beta cells with $15 \mathrm{mmol} / \mathrm{L}$ vs. $0.5 \mathrm{mmol} / \mathrm{L}$ glucose hyperpolarized beta cell mitochondria (Figure 6(c), white bars and exemplary traces). This effect was completely absent after glucolipotoxic culture (Figure 6(c), black bars). Coincubation of glucolipotoxicity-treated beta cells with oltipraz restored mitochondrial reactivity in response to acute glucose stimulation (Figure 6(c), hatched bars). To confirm that the protective effects resulted from an interaction with Nrf2, changes in mitochondrial membrane potential were also determined with DMF. In line with our hypothesis, preincubation with DMF $(50 \mu \mathrm{mol} / \mathrm{L})$ also protected mitochondria against glucolipotoxic damage (Figure 6(d)).
3.6. Influence of Nrf2 Activation on Apoptotic Cell Death. As adequate release of insulin is a result of proper beta cell function and cell mass, the influence of Nrf2 activation on islet cell viability was investigated. Oltipraz $(10 \mu \mathrm{mol} / \mathrm{L})$ did not increase the number of apoptotic islet cells under control conditions (Figure 7(a): $16 \mathrm{~h}$ culture; Figure 7(c): $7 \mathrm{~d}$ culture). This indicates that the reduced secretory response observed after culture with oltipraz under standard conditions was not mediated by elevated beta cell death. When cells were stressed with $\mathrm{H}_{2} \mathrm{O}_{2}$, Nrf2 activation was not able to counteract apoptosis induced by 25 or $100 \mu \mathrm{mol} / \mathrm{L}_{2} \mathrm{O}_{2}(2 \mathrm{~h})$ (Figure 7(b)). Next, we elucidated the influence of glucolipotoxicity on islet cell survival. Induction of apoptosis in the palmitate/glucose model revealed a very high variability in the degree of apoptosis after $7 \mathrm{~d}$ (data not shown). To get a more constant response, the protocol was changed to $33 \mathrm{mmol} / \mathrm{L}$ glucose in combination with the liver $\mathrm{X}$ receptor agonist T0901317 $(10 \mu \mathrm{mol} / \mathrm{L})$. After culturing islet cells under these conditions for 7 days, the fraction of apoptotic cells stably amounted to $\sim 18 \%$. Coculture with oltipraz did not completely prevent but significantly reduce the detrimental effect of glucolipotoxicity (Figure 7(c)).

\section{Discussion}

4.1. Protection against Glucolipotoxicity-Mediated Mitochondrial Impairment by Nrf2. We previously demonstrated that activation of Nrf2 by oltipraz prevented the inhibitory effect of $\mathrm{H}_{2} \mathrm{O}_{2}$ on insulin release [28]. Our current data show that pharmacological activation of Nrf2 also protects pancreatic beta cells from glucolipotoxicity-induced cell damage. We used a combined protocol of medium supplemented with $25 \mathrm{mmol} / \mathrm{L}$ glucose and $100 \mu \mathrm{mol} / \mathrm{L}$ palmitate, applied for up to $48 \mathrm{~h}$, in this study. This clearly supraphysiological glucose concentration was chosen as it was reported for mouse islets that $25 \mathrm{mmol} / \mathrm{L}$ glucose with or without palmitate inhibited the $1^{\text {st }}$ phase of insulin release after short-term incubation (3 d) [29] similar to the situation described for type 2 diabetes mellitus. Of course, one must keep in mind that in vitro models cannot be transferred one-to-one to the complex scenario in vivo. In our hands, the glucolipotoxic in vitro protocol reduced glucose-stimulated insulin secretion to 40 to $50 \%$ (Figure 1(d) and Figures 4(a) and 4(b)). During this $48 \mathrm{~h}$ culture period, impaired islet function was not accompanied by apoptosis even in combination with 0.5 instead of $0.1 \mathrm{mmol} / \mathrm{L}$ palmitate (unpublished data). The inhibition of glucose-induced insulin release detected after glucolipotoxic culture was largely reduced in islets coincubated with oltipraz and almost prevented by DMF (Figures 4(a) and 4(b)). Our experiments reveal that this beneficial effect is mediated by preservation of mitochondrial reactivity. Mitochondria play a central role in the stimulus secretion coupling of beta cells as they couple glucose metabolism to closure of ATP-regulated $\mathrm{K}^{+}$channels, membrane depolarization, and subsequent $\mathrm{Ca}^{2+}$ influx [30]. Prolonged exposure of beta cells to high glucose and lipid concentrations clearly reduced the ability of mitochondria to hyperpolarize in response to acute stimulation with glucose. Glucose-mediated generation of reduction equivalents and 


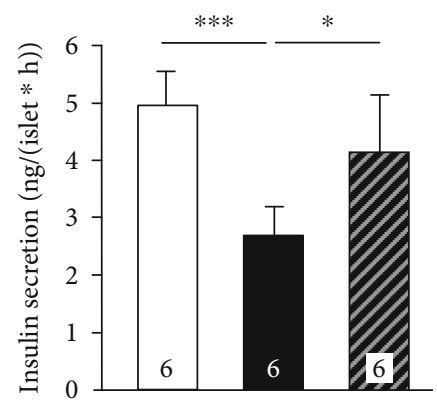

Glucose (mmol/L), $1 \mathrm{~h}$

Glucolipotoxicity (pre-incubation)

Oltipraz $(10 \mu \mathrm{mol} / \mathrm{L})$

(a)

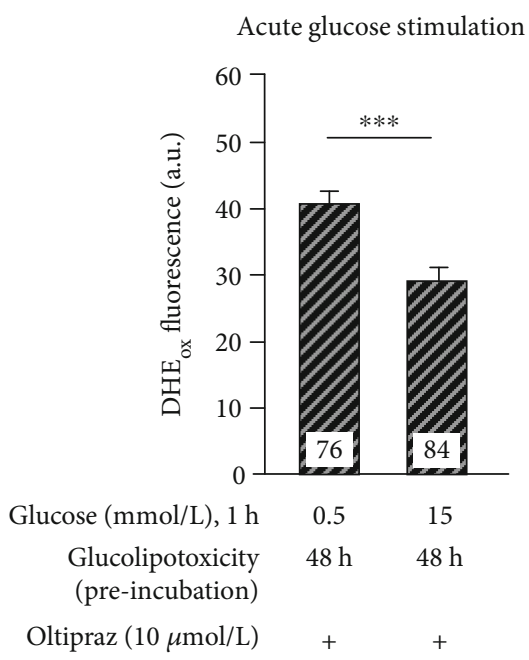

(c)

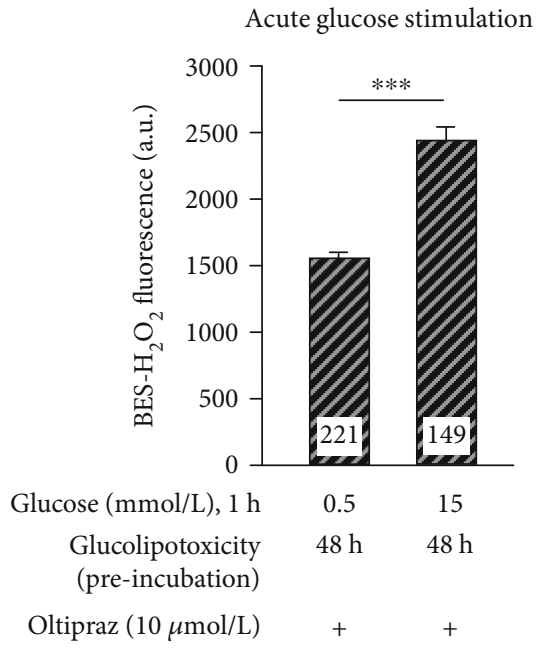

(e)

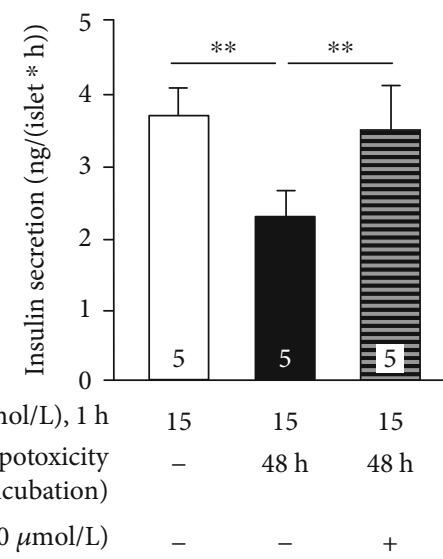

(b)

Acute glucose stimulation

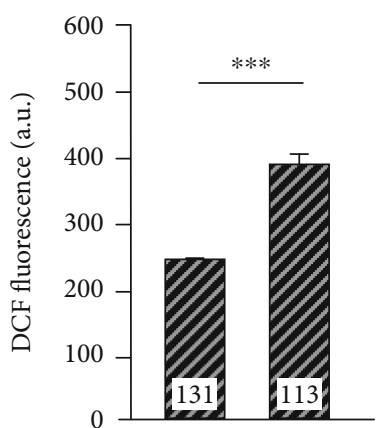

Glucose $(\mathrm{mmol} / \mathrm{L}), 1 \mathrm{~h} \quad 0.5 \quad 15$

Glucolipotoxicity $\quad 48 \mathrm{~h} \quad 48 \mathrm{~h}$

(pre-incubation)

Oltipraz $(10 \mu \mathrm{mol} / \mathrm{L})++$

(d)

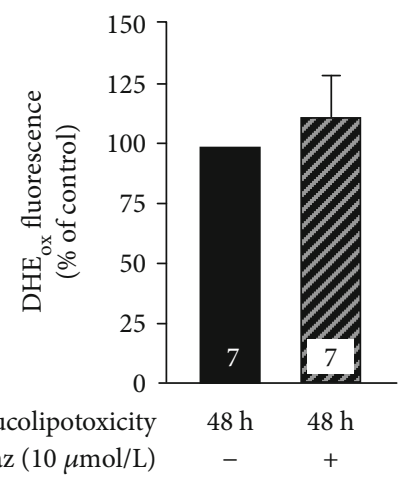

Oltipraz $(10 \mu \mathrm{mol} / \mathrm{L})$

Figure 4: Continued. 


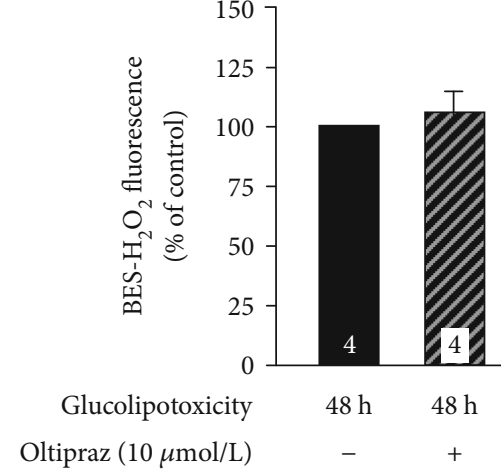

(g)

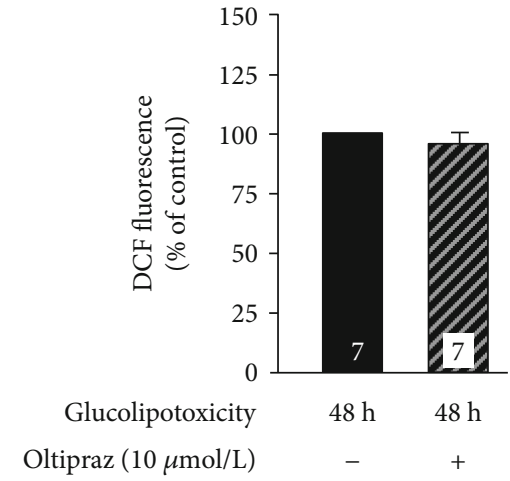

(h)

FIGURE 4: Activation of Nrf2 protects the physiological redox balance and insulin secretion from glucolipotoxic damage. Oltipraz (10 $\mu \mathrm{mol} / \mathrm{L})$ or DMF $(50 \mu \mathrm{mol} / \mathrm{L})$ was added $12-16 \mathrm{~h}$ before changing standard medium to glucolipotoxic medium and during glucolipotoxic culture $(48 \mathrm{~h}) .(\mathrm{a}, \mathrm{b})$ Oltipraz and DMF prevented the detrimental effect of glucolipotoxicity on glucose-stimulated insulin secretion ( $1 \mathrm{~h}$ steadystate incubation). (c-e) Alterations of $\mathrm{DHE}_{\mathrm{ox}}, \mathrm{DCF}$, and $\mathrm{BES}-\mathrm{H}_{2} \mathrm{O}_{2}$ fluorescence in mouse islet cells in response to acute glucose stimulation $(1 \mathrm{~h})$ were preserved in islet cells after culture in glucolipotoxic medium when Nrf2 was activated by oltipraz. (f-h) Redox status of islet cells directly after glucolipotoxic culture was not affected by pretreatment with oltipraz. Numbers in bars indicate the number of independent preparations $\left(\mathrm{a}, \mathrm{b}\right.$, and $\mathrm{f}-\mathrm{h}$ ) or cells $(\mathrm{c}-\mathrm{e}) .{ }^{*} p \leq 0.05,{ }^{* *} p \leq 0.01$, and ${ }^{* * *} p \leq 0.001$.

intracellular ATP was also decreased (Figure 6). These changes are indicative of an impaired activation of mitochondrial respiratory chains and are in agreement with the observations of others described for insulin-secreting cell lines as well as primary islet cells [31-33]. Activation of Nrf2 restored glucose responsiveness with respect to all metabolic parameters. Prevention of mitochondrial damage by Nrf2 has already been described for other tissues: In endothelial cells, activation of $\mathrm{Nrf} 2$ protected against mitochondrial depolarization and release of cytochrome $c$ in response to high glucose concentrations. In renal tubular cells of obese and glucose intolerant $\mathrm{db} / \mathrm{db}$ mice, an Nrf2-dependent pathway reduced mitochondrial fragmentation and activation of caspase $3[34,35]$.

4.2. Effects of Glucolipotoxicity and Nrf2 Activation on Intracellular ROS and Redox Status. While ROS have only been seen in a negative context with respect to adequate beta cell function for a long time, the role of ROS has been reinterpreted during the last decade. There is evidence that a certain amount of $\mathrm{H}_{2} \mathrm{O}_{2}$ supports insulin release [24], whereas dramatically increased accumulation results in severe cell damage [36]. ROS, like superoxide radical anions or hydroxyl radicals, are highly reactive and quickly oxidize membrane proteins or lipids. With respect to the fate of free radicals produced in excess, the situation is complex. Most investigations, describing an increase in ROS in response to culture with high glucose and/or lipid concentrations, were done with insulin-secreting cell lines, mainly INS-1 cells and not with primary islets [37-39]. Furthermore, many conclusions were drawn by monitoring DCDHF oxidation, which is not specific for a certain kind of ROS but rather indicates elevated oxidative reactions of different origin [40]. For primary tissue, data is limited. Our results show that those ROS, which are sensitive to the two fluorescent dyes $\mathrm{BES}-\mathrm{H}_{2} \mathrm{O}_{2}$ and DHE, do not accumulate in beta cells after glucolipotoxic challenge for up to $48 \mathrm{~h}$ but finally even decrease. The same holds true for DCF fluorescence (Figure 2). BES- $\mathrm{H}_{2} \mathrm{O}_{2}$ is reported to detect $\mathrm{H}_{2} \mathrm{O}_{2}$ whereas DHE is preferentially oxidized by superoxide radical anion $[25,41]$. In line with our results, Moore et al. observed no elevation of oxidative stress levels in rat islet cells cultured with $500 \mu \mathrm{mol} / \mathrm{L}$ palmitate and $16.7 \mathrm{mmol} / \mathrm{L}$ glucose for $72 \mathrm{~h} \mathrm{[42]} \mathrm{and} \mathrm{Martens} \mathrm{et} \mathrm{al.} \mathrm{showed}$ a reduced concentration of superoxide radical anions in rat islet cells after culture in medium supplemented with $20 \mathrm{vs}$. $6 \mathrm{mmol} / \mathrm{L}$ glucose [43]. Even with a high concentration of palmitate $(1 \mathrm{mmol} / \mathrm{L}$, combined with $33 \mathrm{mmol} / \mathrm{L}$ glucose), DCF fluorescence decreased after 3 days of culture in mouse islet cells [33]. By contrast, elevation of DCF fluorescence by $400 \mu \mathrm{mol} / \mathrm{L}$ palmitate or oleate was reported by others for rodent islets [44, 45]. The reasons for these discrepancies remain unclear, but in most cases, results cannot be directly compared due to variations in concentration, albumin binding, the nature of free fatty acid, or exposure time. Even though pancreatic islets are very sensitive to oxidative stress, it is known that they can align to such situations by modulation of antioxidant defense mechanisms [36]. An important observation of our investigation is that glucolipotoxicity prevents glucose from acutely changing intracellular redox balance irrespective of the fluorescence dye used for detection (Figures 1(a)-1(c)). Most likely, mitochondrial damage plays a major role for this loss of acute response. Our data clearly show that strengthening Nrf2-mediated pathways restores the physiological changes in ROS induced by acute glucose stimulation. Although activation of Nrf2 did not affect ROS accumulation in glucolipotoxicity-damaged beta cells per se (Figures 4(f)-4(h)), glucose-induced alterations of ROS, i.e., an increase in BES- $\mathrm{H}_{2} \mathrm{O}_{2}$ and a decrease in DHE $\mathrm{Dx}_{\mathrm{ox}}$ fluorescence in response to acute stimulation with $15 \mathrm{vs} .0 .5 \mathrm{mmol} / \mathrm{L}$ glucose, reappeared when cells were treated with oltipraz (Figures 4(c)-4(e)). We hypothesize that this reflects increased flux of radicals, more precisely, the generation of superoxide radical anions as a by-product of mitochondrial metabolism during glucose stimulation and its fast 


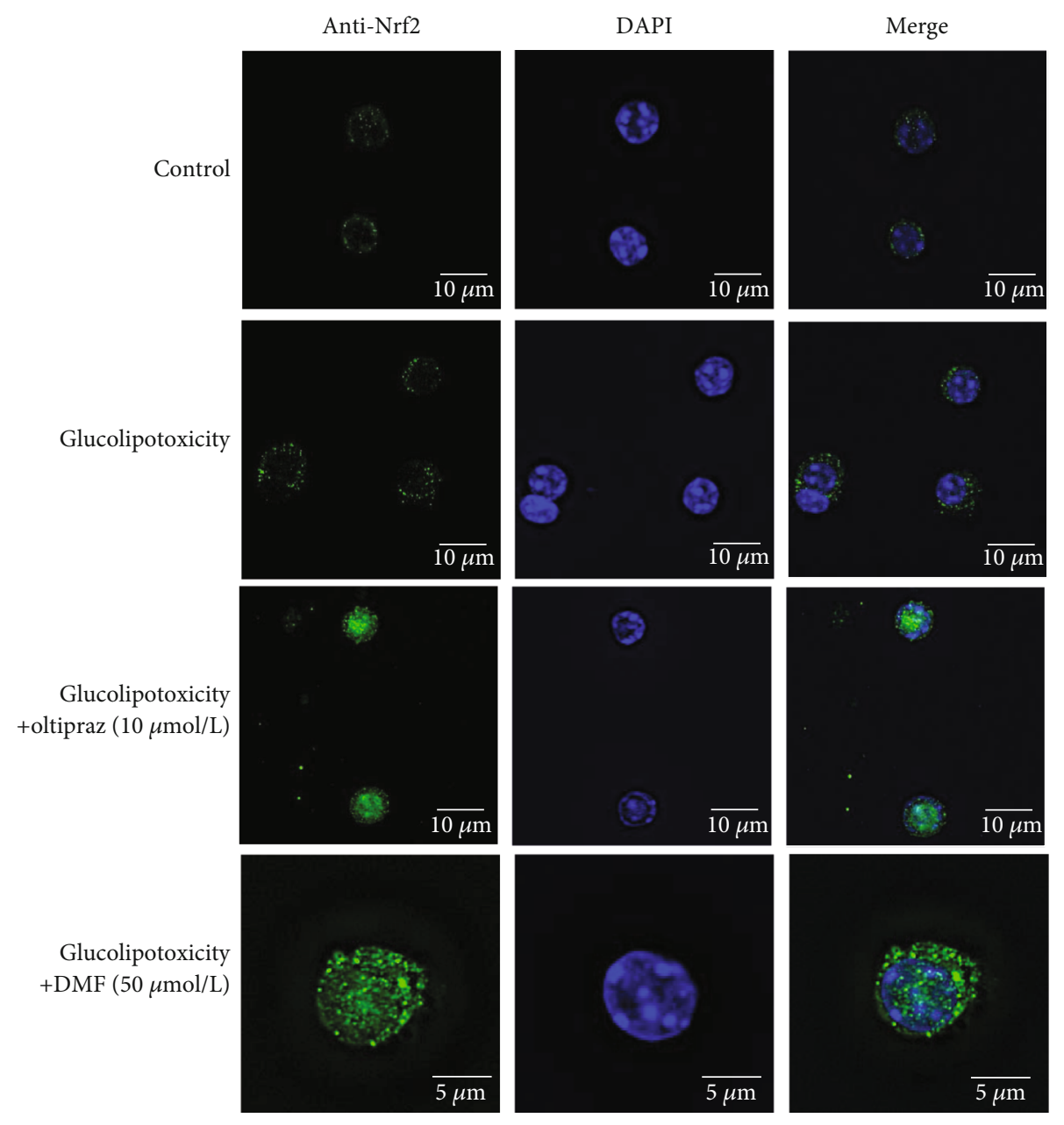

(a)

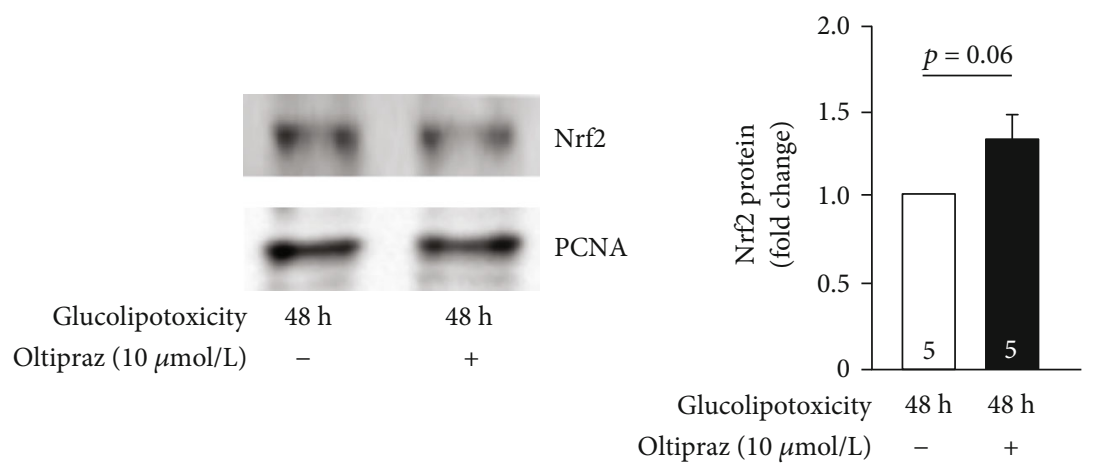

(b)

Figure 5: Oltipraz and DMF alter Nrf2 distribution in islet cells stressed by glucolipotoxicity. Cells were treated by Nrf2 activators and cultured in glucolipotoxic medium as described for Figure 4. (a) Representative images out of 3-5 mouse preparations are shown (left: anti-Nrf2 antibody (green), middle: DAPI staining (blue), and right: overlay). Addition of oltipraz $(10 \mu \mathrm{mol} / \mathrm{L})$ or $\mathrm{DMF}(50 \mu \mathrm{mol} / \mathrm{L})$ during glucolipotoxic culture increased nuclear Nrf2 localization. (b) Islets were lysed and analyzed by Western blot after $48 \mathrm{~h}$ culture with or without oltipraz. Representative blots for Nrf2 protein $(95 \mathrm{kDa})$ and the housekeeping protein PCNA $(36 \mathrm{kDa})$ are shown. Coculture with oltipraz did not significantly elevate Nrf2 protein.

dismutation to $\mathrm{H}_{2} \mathrm{O}_{2}$. Taken together, our data indicate that Nrf2-activating compounds protect against mitochondrial failure which is reflected by restoration of the acute shifts in ROS in response to the two different glucose con- centrations. The data also show that not every change is normalized by treatment with oltipraz, but obviously, the glucolipotoxicity-induced lowering of ROS accumulation during culture is not decisive in this context. 


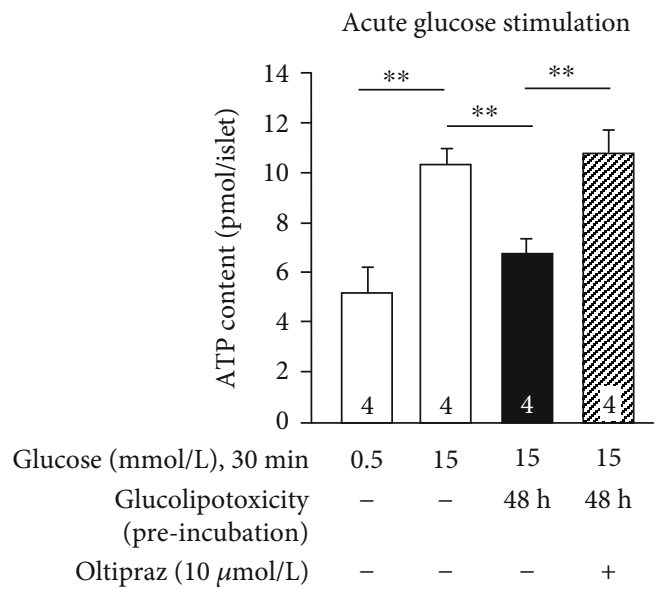

(a)

Acute glucose stimulation
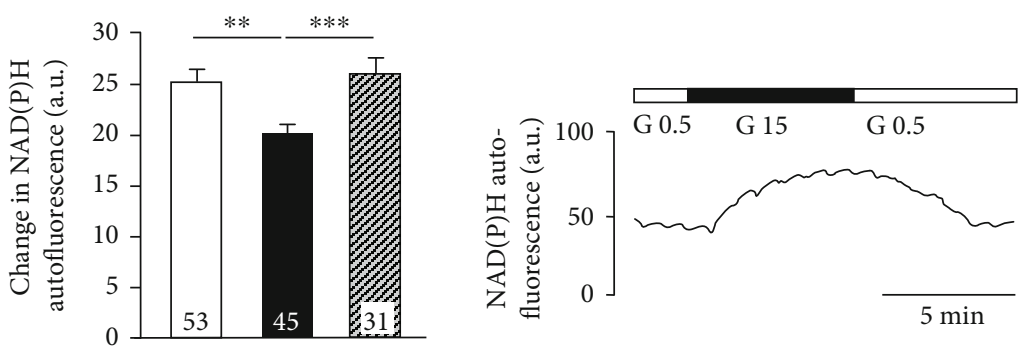

Glucolipotoxicity

(pre-incubation)

$48 \mathrm{~h} \quad 48 \mathrm{~h}$

Oltipraz $(10 \mu \mathrm{mol} / \mathrm{L})$

(b)
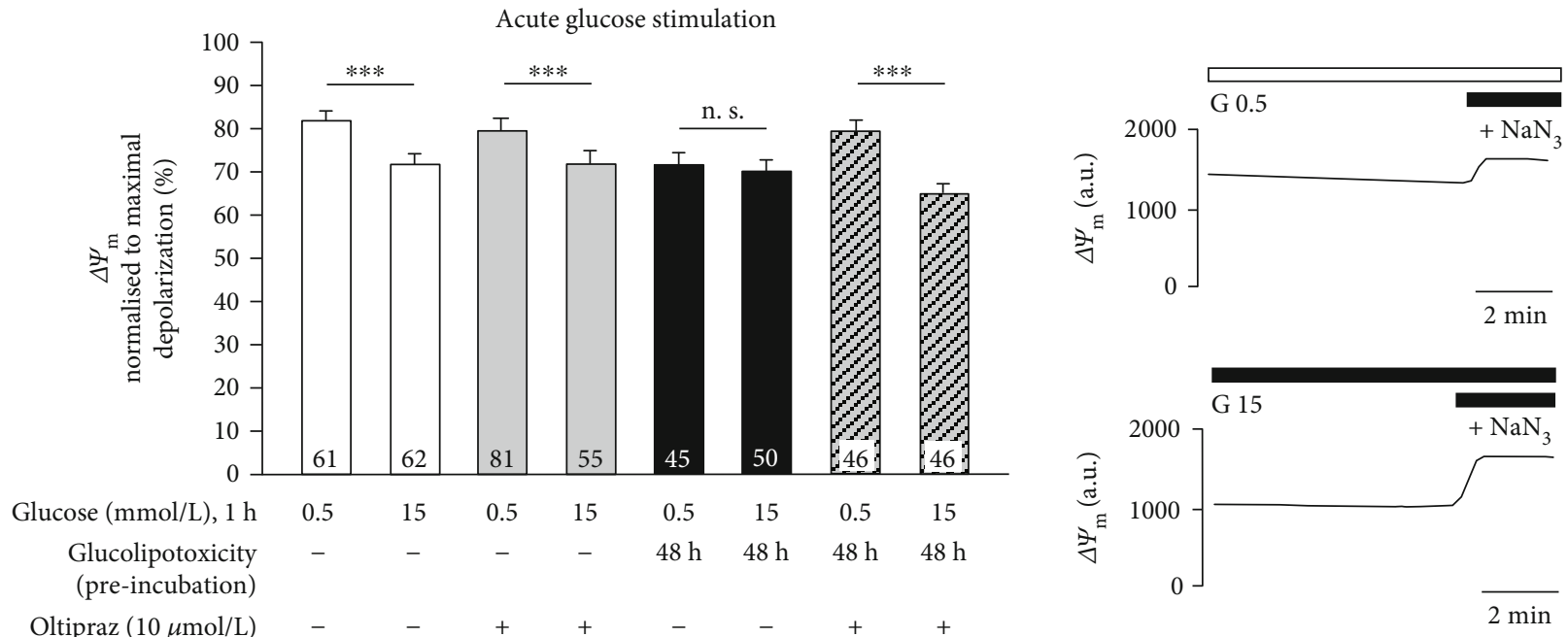

(c)

FIgURE 6: Continued. 


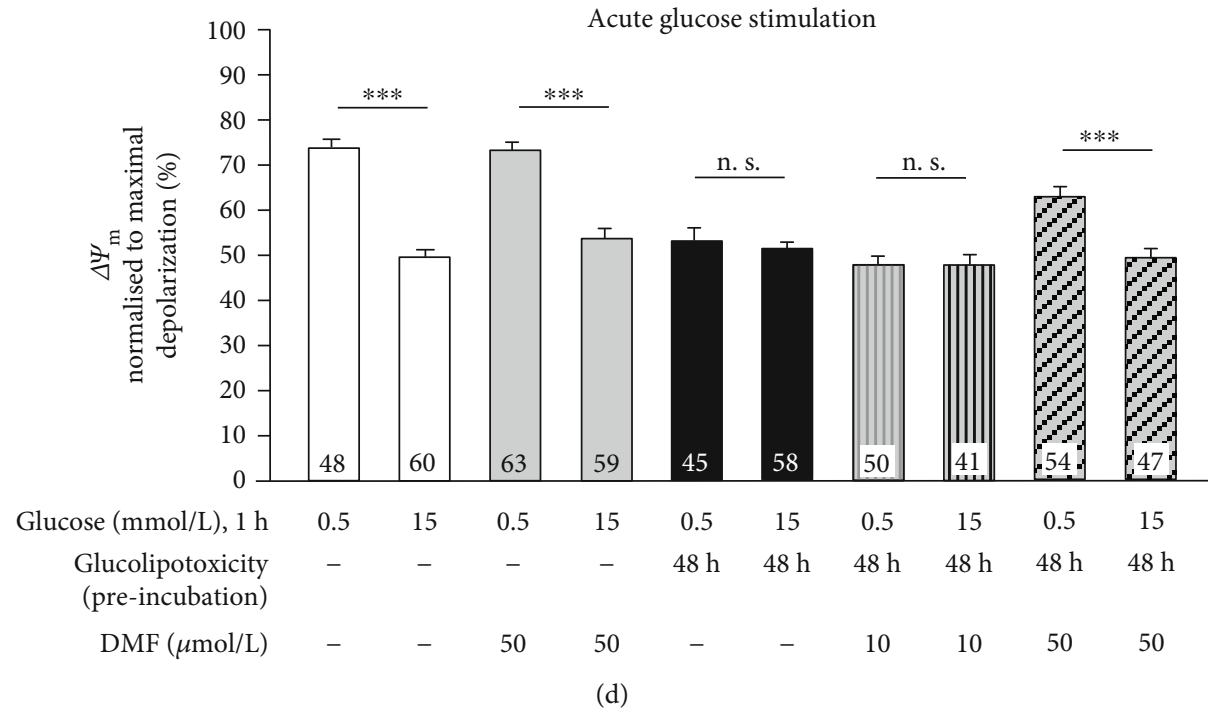

FIGURE 6: Activation of Nrf2 prevents the inhibitory effects of glucolipotoxicity on ATP content, glucose-induced generation of NAD(P)H, and mitochondrial function. Oltipraz $(10 \mu \mathrm{mol} / \mathrm{L})$ or DMF $(10$ or $50 \mu \mathrm{mol} / \mathrm{L})$ was added to isolated murine islet cells $12-16 \mathrm{~h}$ before changing standard medium to glucolipotoxic medium and during glucolipotoxic culture $(48 \mathrm{~h})$. (a) Glucose-stimulated rise in ATP content was decreased after glucolipotoxic culture. Oltipraz protected against this. (b) Glucose-stimulated elevation of $\mathrm{NAD}(\mathrm{P}) \mathrm{H}$ autofluorescence was reduced after glucolipotoxic culture. This was completely prevented by oltipraz. A representative recording after culture in standard medium is shown on the right. (, d) Mitochondrial membrane potential $\left(\Delta \Psi_{\mathrm{m}}\right)$ was determined in response to $1 \mathrm{~h}$ stimulation with 0.5 vs. $15 \mathrm{mmol} / \mathrm{L}$ glucose after culture in control (white and grey bars) or glucolipotoxic (black and hatched bars) medium in the presence or absence of Nrf2 activators. Mitochondria damaged by glucolipotoxicity were unresponsive to glucose (black bars). Oltipraz or DMF protected against this (hatched bars). In (c), representative recordings for control conditions are shown on the right. Numbers in bars indicate the number of independent preparations (a) or cells (b-d). ${ }^{* *} p \leq 0.01$ and ${ }^{* * *} p \leq 0.001$; n. $\mathrm{s}$. : not significant.

4.3. Negative Effects of Nrf2 Activation. Importantly, our data reveal that Nrf2 activation is only beneficial for beta cells under pathophysiological conditions. In islets not challenged by nutrient excess, treatment with either oltipraz or DMF dramatically inhibited glucose-stimulated insulin release (Figures 3(a) and 3(b)). Remarkably, the reduction of $\mathrm{DHE}_{\text {ox }}$-detectable ROS in response to acute stimulation with glucose was completely prevented after Nrf2 activation and the rise in DCF fluorescence was lowered (Figures 3(c) and $3(d))$. This observation is in agreement with the idea that overactivation of antioxidant capacity disturbs the physiological redox balance. In line with this hypothesis, exposure of INS-1 cells to arsenite for $96 \mathrm{~h}$ elevated Nrf2 levels, reduced oxidation reactions, but decreased the stimulatory effect of $20 \mathrm{mmol} / \mathrm{L}$ glucose on insulin secretion [46]. An increase in $\mathrm{H}_{2} \mathrm{O}_{2}$ production, induced by an acute rise in the glucose concentration, is suggested to function as part of a second messenger system that contributes to glucose-regulated insulin release, but discussion remains controversial [24, 47, 48]. Our results imply that a glucose-mediated rise in $\mathrm{H}_{2} \mathrm{O}_{2}$ beyond the physiological level is associated with impaired insulin release. Presumably, high concentrations of $\mathrm{H}_{2} \mathrm{O}_{2}$ together with accumulation of superoxide radical anions trigger beta cell dysfunction in this context. A dual role for beta cell regulation, i.e., acute, stimulatory effects at low concentrations and a negative impact at higher concentrations, is also postulated for nitric oxide [30]. The altered balance in ROS described in our study for "healthy" beta cells in response to oltipraz could be caused by subtle effects of long-lasting Nrf2 activation on mitochondrial respiratory chains. Although glucose did not lose its ability to hyperpolarize the mitochondria, the degree of mitochondrial activation tended to be smaller compared to control, when Nrf2 was activated by oltipraz or DMF (Figures 6(c) and 6(d), grey $v s$. white bars). Furthermore, temporarily elevated levels of both, $\mathrm{H}_{2} \mathrm{O}_{2}$ and superoxide radical anions, during acute glucose stimulation (compared to low glucose) might directly disturb signaling steps downstream to mitochondria.

4.4. Influence of Nrf2 Activation on Beta Cell Mass. Our experiments reveal that the proapoptotic effect of $\mathrm{H}_{2} \mathrm{O}_{2}$ in islet cells could not be prevented by Nrf2 activation. By contrast, oltipraz drastically reduced islet cell death induced by increased intracellular lipid synthesis and high glucose by $\sim 65 \%$ (Figures $7\left(\right.$ b) and $7(\mathrm{c})$ ). This suggests that $\mathrm{H}_{2} \mathrm{O}_{2}$ is not decisive for glucolipotoxicity-mediated cell death. Partial protection against $\mathrm{H}_{2} \mathrm{O}_{2}$-induced cell death was described for the Nrf2 activator dh404 (dihydro-CDDO-trifluoroethyl amide) in human and rat islets $[18,19]$ or MIN-6 cells [21]. To our knowledge, the influence of Nrf2 on glucolipotoxicity-induced apoptosis has not yet been investigated in primary beta cells. Treatment of insulin-secreting INS- 1 cells with a high glucose concentration of $25 \mathrm{mmol} / \mathrm{L}$ elevated apoptosis. Protection against this by the natural product honokiol was associated with translocation of Nrf2 to the nucleus [49]. In INS-1E cells, lipotoxic conditions 


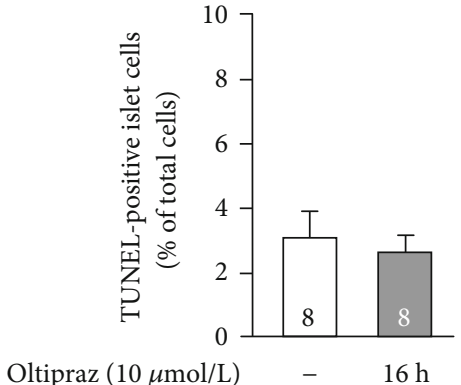

(a)

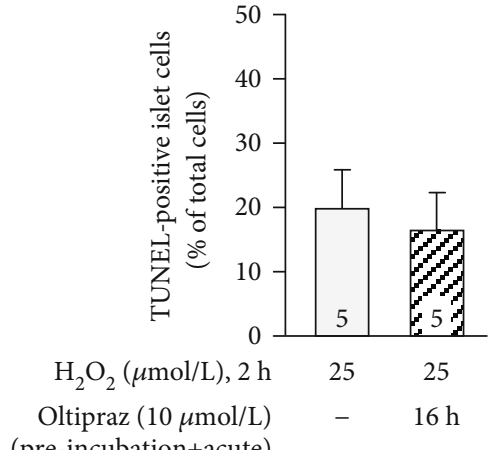

(pre-incubation+acute)

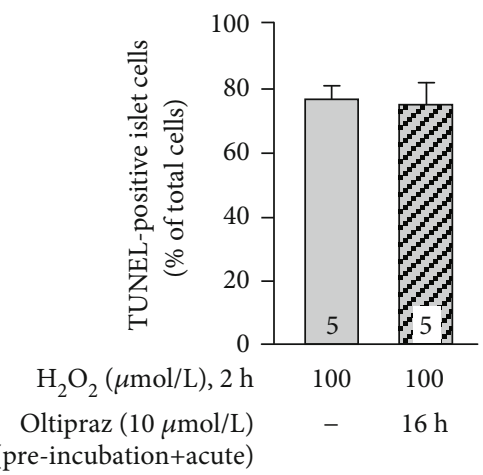

(b)

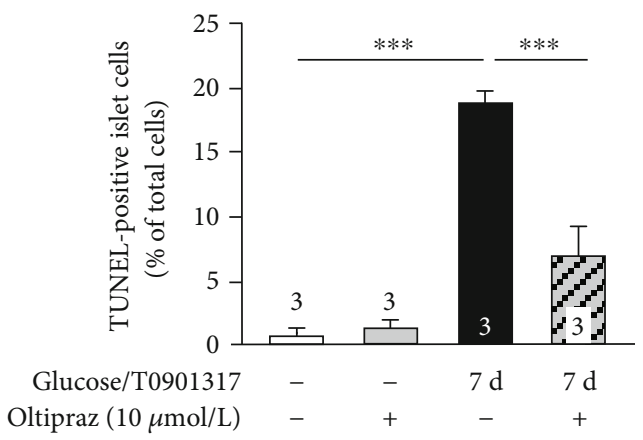

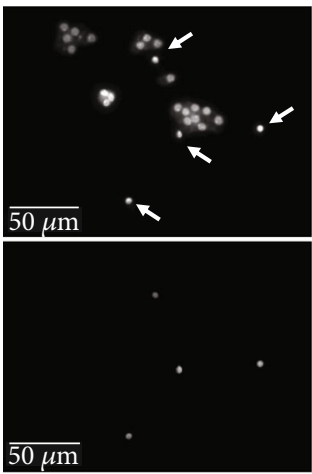

Glucolipotoxicity

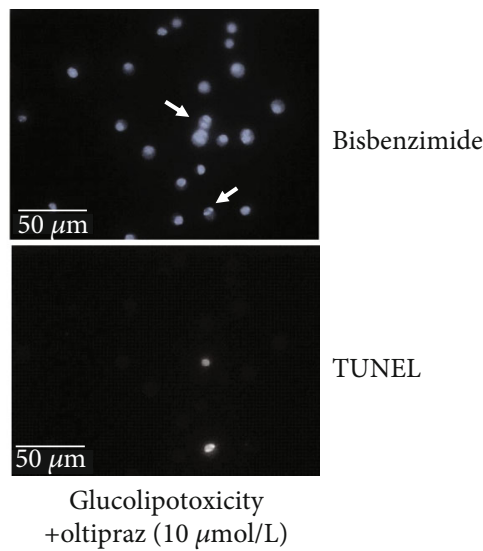

(c)

FIGURE 7: Nrf2 activation influences cell viability of islet cells. (a) Culturing mouse islet cells in standard medium with or without oltipraz $(10 \mu \mathrm{mol} / \mathrm{L})$ for approximately $16 \mathrm{~h}$ did not affect the fraction of apoptotic cells. (b) After the $16 \mathrm{~h}$ culture period, cells were stressed by 25 or $100 \mu \mathrm{mol} / \mathrm{L} \mathrm{H}_{2} \mathrm{O}_{2}$ in the continued presence of oltipraz for $2 \mathrm{~h}$. Apoptosis tends to be reduced by oltipraz in those cells exposed to the lower $\mathrm{H}_{2} \mathrm{O}_{2}$ concentration (left diagram), but not when $\mathrm{H}_{2} \mathrm{O}_{2}$-induced cell damage was high (right diagram). Note that scaling is different to provide adequate resolution. (c) After the $16 \mathrm{~h}$ culture period, medium was exchanged and culture was continued in the presence of $33 \mathrm{mmol} / \mathrm{L}$ glucose and $10 \mu \mathrm{mol} / \mathrm{L}$ T0901317 in the presence or absence of oltipraz for 7 days. Nrf 2 activation markedly reduced the fraction of apoptotic cells. Images of one representative experiment are shown on the right. The upper images illustrate nuclear staining. Arrows indicate TUNEL-positive cells shown in the lower traces. Numbers in bars indicate the number of independent preparations. *** $p \leq 0.001$.

(500 $\mu \mathrm{mol} / \mathrm{L}$ palmitate) transiently elevated Nrf2 protein content, thereby dampening stress-induced cell death. This effect was lost after prolonged exposure $(16 \mathrm{~h})$ to lipotoxicity. The underlying mechanisms are not entirely clear but seem to involve a novel pathway for regulation of $\mathrm{Nrf} 2$, mediated by ER-located thrombospondin [20]. The importance of Nrf2 for beta cell mass was also shown in transgenic animal models with elevated activity of iNOS. Islets of mice overexpressing iNOS displayed increased proliferation when Keap1 was knocked out concurrently compared to those without elimination of the Nrf2-inactivating protein [50].

In summary, our data demonstrate that protection of mitochondrial function is a key element of the Nrf2mediated defense mechanism against glucolipotoxicity in beta cells. Preservation of mitochondrial activity by Nrf2 activators does not interact with the general redox status of beta cells at stress conditions but restores the physiological, fast alterations in ROS turnover, as well as insulin release in response to acute stimulation with glucose. This study emphasizes the importance of dynamic changes in redox homeostasis for the regulation of insulin release, which is severely affected by abnormally elevated glucose and lipid load. Targeting Nrf2 in patients suffering from dyslipidemia and glucose intolerance could extend current options for the treatment of metabolic disease.
Abbreviations
a.u.: $\quad$ Arbitrary fluorescence units
BES- $\mathrm{H}_{2} \mathrm{O}_{2}$ : $\quad 3^{\prime}$-O-acetyl- $6^{\prime}$-O-pentafluorobenzenesulfonyl- $2^{\prime}-7^{\prime}$-difluorofluorescein
DAPI: $\quad 4^{\prime}, 6$-Diamidine- $2^{\prime}$-phenylindole
DCDHF-DA: $2^{\prime}, 7^{\prime}$-Dichlorodihydrofluorescein-diacetate
DCF: $\quad 2^{\prime}, 7^{\prime}$-Dichlorofluorescein
DHE: Dihydroethidium
$\mathrm{DHE}_{\mathrm{ox}}$ : $\quad$ Oxidation products of dihydroethidium
DMF: Dimethyl fumarate 


$\begin{array}{ll}\text { iNOS: } & \text { Inducible nitric oxide synthase } \\ \text { Nrf2: } & \text { Nuclear factor erythroid 2p45-related factor } 2 \\ \text { PCNA: } & \text { Proliferating cell nuclear antigen } \\ \text { ROS: } & \text { Reactive oxygen species. }\end{array}$

\section{Data Availability}

The data used to support the findings of this study are available from the corresponding author upon request.

\section{Conflicts of Interest}

The authors declare no conflict of interest.

\section{Authors' Contributions}

J. S., D. B., D. M., and L. M. researched and analyzed the data and contributed to the discussion. M. E. designed the experiments, contributed to the analysis, and contributed to the discussion. M. D. designed the experiments, supervised the study, and wrote and edited the manuscript. All authors read and approved the final manuscript. M. D. is the guarantor of this work and takes responsibility for integrity and accuracy of data generation and evaluation. Johanna Schultheis and Dirk Beckmann contributed equally to this work.

\section{Acknowledgments}

We thank Melanie Arning for the excellent technical assistance. Parts of this work were supported by grants of the Deutsche Forschungsgemeinschaft to M.D. (DU 425/2-1 and INST 211/647-1 FUGG).

\section{Supplementary Materials}

Comparison of the effect of substimulatory glucose concentrations on acute changes in ROS balance. Islet cells were acutely treated with $0.5,3$, or $15 \mathrm{mmol} / \mathrm{L}$ glucose. Levels of $\mathrm{DHE}_{\text {ox }}(\mathrm{A})$ and DCF (B) fluorescence were similar with the two substimulatory glucose concentrations but change in response to $15 \mathrm{mmol} / \mathrm{L}$ glucose. Numbers in bars indicate the number of cells. ${ }^{* * *} p \leq 0.001$. (Supplementary Materials)

\section{References}

[1] M. Tiedge, S. Lortz, J. Drinkgern, and S. Lenzen, "Relation between antioxidant enzyme gene expression and antioxidative defense status of insulin-producing cells," Diabetes, vol. 46, no. 11, pp. 1733-1742, 1997.

[2] T. B. Mysore, T. A. Shinkel, J. Collins et al., "Overexpression of glutathione peroxidase with two isoforms of superoxide dismutase protects mouse islets from oxidative injury and improves islet graft function," Diabetes, vol. 54, no. 7, pp. 2109-2116, 2005.

[3] S. Lortz and M. Tiedge, "Sequential inactivation of reactive oxygen species by combined overexpression of SOD isoforms and catalase in insulin-producing cells," Free Radical Biology \& Medicine, vol. 34, no. 6, pp. 683-688, 2003.

[4] Y. C. Kim, H. Masutani, Y. Yamaguchi, K. Itoh, M. Yamamoto, and J. Yodoi, "Hemin-induced activation of the thioredoxin gene by Nrf2," Journal of Biological Chemistry, vol. 276, no. 21, pp. 18399-18406, 2001.

[5] J. Alam, D. Stewart, C. Touchard, S. Boinapally, A. M. K. Choi, and J. L. Cook, "Nrf2, a Cap'n'Collar transcription factor, regulates induction of the heme oxygenase-1 gene," The Journal of Biological Chemistry, vol. 274, no. 37, pp. 26071-26078, 1999.

[6] H. Dreger, K. Westphal, A. Weller et al., "Nrf2-dependent upregulation of antioxidative enzymes: a novel pathway for proteasome inhibitor-mediated cardioprotection," Cardiovascular Research, vol. 83, no. 2, pp. 354-361, 2009.

[7] T. Jiang, Z. Huang, Y. Lin, Z. Zhang, D. Fang, and D. D. Zhang, "The protective role of Nrf2 in streptozotocin-induced diabetic nephropathy," Diabetes, vol. 59, no. 4, pp. 850-860, 2010.

[8] Q. Zhong, M. Mishra, and R. A. Kowluru, "Transcription factor Nrf2-mediated antioxidant defense system in the development of diabetic retinopathy," Investigative Ophthalmology \& Visual Science, vol. 54, no. 6, pp. 3941-3948, 2013.

[9] Y. J. Lee, S. B. Kwon, J. M. An et al., "Increased protein oxidation and decreased expression of nuclear factor E2-related factor 2 protein in skin tissue of patients with diabetes," Clinical and Experimental Dermatology, vol. 40, no. 2, pp. 192-200, 2015.

[10] M. S. Bitar and F. Al-Mulla, "A defect in Nrf2 signaling constitutes a mechanism for cellular stress hypersensitivity in a genetic rat model of type 2 diabetes," American Journal of Physiology. Endocrinology and Metabolism, vol. 301, no. 6, pp. E1119-E1129, 2011.

[11] Z. Yu, W. Shao, Y. Chiang et al., "Oltipraz upregulates the nuclear factor (erythroid-derived 2)-like 2 [corrected](NRF2) antioxidant system and prevents insulin resistance and obesity induced by a high-fat diet in C57BL/6J mice," Diabetologia, vol. 54, no. 4, pp. 922-934, 2011.

[12] T. Abebe, J. Mahadevan, L. Bogachus et al., "Nrf2/antioxidant pathway mediates $\beta$ cell self-repair after damage by high-fat diet-induced oxidative stress," JCI Insight, vol. 2, no. 24, 2017.

[13] R. Robson, A. R. Kundur, and I. Singh, "Oxidative stress biomarkers in type 2 diabetes mellitus for assessment of cardiovascular disease risk," Diabetes and Metabolic Syndrome: Clinical Research and Reviews, vol. 12, no. 3, pp. 455-462, 2018.

[14] A. Uruno, Y. Furusawa, Y. Yagishita et al., "The Keap1-Nrf2 system prevents onset of diabetes mellitus," Molecular and Cellular Biology, vol. 33, no. 15, pp. 2996-3010, 2013.

[15] S. Shin, J. Wakabayashi, M. S. Yates et al., "Role of Nrf2 in prevention of high-fat diet-induced obesity by synthetic triterpenoid CDDO-imidazolide," European Journal of Pharmacology, vol. 620, no. 1-3, pp. 138-144, 2009.

[16] C. Sampath, M. R. Rashid, S. Sang, and M. Ahmedna, "Specific bioactive compounds in ginger and apple alleviate hyperglycemia in mice with high fat diet-induced obesity via Nrf2 mediated pathway," Food Chemistry, vol. 226, pp. 79-88, 2017.

[17] J. Pi, Q. Zhang, J. Fu et al., "ROS signaling, oxidative stress and Nrf2 in pancreatic beta-cell function," Toxicology and Applied Pharmacology, vol. 244, no. 1, pp. 77-83, 2010.

[18] Y. Masuda, N. D. Vaziri, S. Li et al., "The effect of Nrf2 pathway activation on human pancreatic islet cells," PLoS One, vol. 10, no. 6, p. e0131012, 2015.

[19] W. Li, W. Wu, H. Song et al., "Targeting Nrf2 by dihydroCDDO-trifluoroethyl amide enhances autophagic clearance and viability of $\beta$-cells in a setting of oxidative stress," FEBS Letters, vol. 588, no. 12, pp. 2115-2124, 2014. 
[20] D. A. Cunha, M. Cito, P.-O. Carlsson et al., “Thrombospondin 1 protects pancreatic $\beta$-cells from lipotoxicity via the PERKNRF2 pathway," Cell Death and Differentiation, vol. 23, no. 12, pp. 1995-2006, 2016.

[21] J. Fu, H. Zheng, H. Wang et al., "Protective Role of Nuclear Factor E2-Related Factor 2 against Acute Oxidative StressInduced Pancreatic $\beta$-Cell Damage," Oxidative Medicine and Cellular Longevity, vol. 2015, Article ID 639191, 12 pages, 2015.

[22] J. A. David, W. J. Rifkin, P. S. Rabbani, and D. J. Ceradini, “The Nrf2/Keap1/ARE pathway and oxidative stress as a therapeutic target in type II diabetes mellitus," Journal of Diabetes Research, vol. 2017, Article ID 4826724, 15 pages, 2017.

[23] C. Leloup, C. Tourrel-Cuzin, C. Magnan et al., "Mitochondrial reactive oxygen species are obligatory signals for glucoseinduced insulin secretion," Diabetes, vol. 58, no. 3, pp. 673681, 2009.

[24] J. Pi, Y. Bai, Q. Zhang et al., "Reactive oxygen species as a signal in glucose-stimulated insulin secretion," Diabetes, vol. 56, no. 7, pp. 1783-1791, 2007.

[25] H. Maeda, Y. Fukuyasu, S. Yoshida et al., "Fluorescent probes for hydrogen peroxide based on a non-oxidative mechanism," Angewandte Chemie (International Ed. in English), vol. 43, no. 18, pp. 2389-2391, 2004.

[26] M. F. Graciano, M. Valle, A. Kowluru, R. Curi, and A. Carpinelli, "Regulation of insulin secretion and reactive oxygen species production by free fatty acids in pancreatic islets," Islets, vol. 3, no. 5, pp. 213-223, 2011.

[27] P. Ježek, A. Dlasková, and L. Plecitá-Hlavatá, "Redox homeostasis in pancreatic beta cells," Oxidative Medicine and Cellular Longevity, vol. 2012, Article ID 932838, 2012.

[28] A. Edalat, P. Schulte-Mecklenbeck, C. Bauer et al., "Mitochondrial succinate dehydrogenase is involved in stimulussecretion coupling and endogenous ROS formation in murine beta cells," Diabetologia, vol. 58, no. 7, pp. 1532-1541, 2015.

[29] N. M. Doliba, Q. Liu, C. Li et al., "Inhibition of cholinergic potentiation of insulin secretion from pancreatic islets by chronic elevation of glucose and fatty acids: protection by casein kinase 2 inhibitor," Mol. Metab., vol. 6, no. 10, pp. 1240-1253, 2017.

[30] G. Drews, P. Krippeit-Drews, and M. Düfer, "Electrophysiology of islet cells," in Islets of Langerhans, S. Islam, Ed., pp. 1-51, Springer Netherlands, Dordrecht, 2. ed edition, 2014.

[31] R. Köhnke, J. Mei, M. Park, D. A. York, and C. ErlansonAlbertsson, "Fatty acids and glucose in high concentration down-regulates ATP synthase beta-subunit protein expression in INS-1 cells," Nutritional Neuroscience, vol. 10, no. 5-6, pp. 273-278, 2007.

[32] B. P. Somesh, M. K. Verma, M. K. Sadasivuni et al., "Chronic glucolipotoxic conditions in pancreatic islets impair insulin secretion due to dysregulated calcium dynamics, glucose responsiveness and mitochondrial activity," BMC Cell Biology, vol. 14, no. 1, p. 31, 2013.

[33] M. Barroso Oquendo, N. Layer, R. Wagner, P. Krippeit-Drews, and G. Drews, "Energy depletion and not ROS formation is a crucial step of glucolipotoxicity (GLTx) in pancreatic beta cells," Pflügers Archiv - European Journal of Physiology, vol. 470, no. 3, pp. 537-547, 2018.

[34] L. Xiao, X. Xu, F. Zhang et al., "The mitochondria-targeted antioxidant MitoQ ameliorated tubular injury mediated by mitophagy in diabetic kidney disease via Nrf2/PINK1," Redox Biology, vol. 11, pp. 297-311, 2017.

[35] Z.-Y. Zhong and Y. Tang, "Upregulation of periostin prevents high glucose-induced mitochondrial apoptosis in human umbilical vein endothelial cells via activation of $\mathrm{Nrf} 2 / \mathrm{HO}-1$ signaling," Cellular Physiology and Biochemistry, vol. 39, no. 1, pp. 71-80, 2016.

[36] G. Drews, P. Krippeit-Drews, and M. Düfer, "Oxidative stress and beta-cell dysfunction," Pflügers Archiv - European Journal of Physiology, vol. 460, no. 4, pp. 703-718, 2010.

[37] M. Maris, S. Robert, E. Waelkens et al., "Role of the saturated nonesterified fatty acid palmitate in beta cell dysfunction," Journal of Proteome Research, vol. 12, no. 1, pp. 347362, 2013.

[38] G. R. Ryu, J. M. Yoo, E. Lee, S.-H. Ko, Y.-B. Ahn, and K.-H. Song, "Decreased expression and induced nucleocytoplasmic translocation of pancreatic and duodenal homeobox 1 in INS-1 cells exposed to high glucose and palmitate," Diabetes and Metabolism Journal, vol. 35, no. 1, pp. 65-71, 2011.

[39] X. Quan, L. Zhang, Y. Li, and C. Liang, "TCF2 attenuates FFAinduced damage in islet $\beta$-cells by regulating production of insulin and ROS," International Journal of Molecular Sciences, vol. 15, no. 8, pp. 13317-13332, 2014.

[40] B. Kalyanaraman, V. Darley-Usmar, K. J. A. Davies et al., "Measuring reactive oxygen and nitrogen species with fluorescent probes: challenges and limitations," Free Radical Biology \& Medicine, vol. 52, no. 1, pp. 1-6, 2012.

[41] H. Zhao, S. Kalivendi, H. Zhang et al., "Superoxide reacts with hydroethidine but forms a fluorescent product that is distinctly different from ethidium: potential implications in intracellular fluorescence detection of superoxide," Free Radical Biology \& Medicine, vol. 34, no. 11, pp. 1359-1368, 2003.

[42] P. C. Moore, M. A. Ugas, D. K. Hagman, S. D. Parazzoli, and V. Poitout, "Evidence against the involvement of oxidative stress in fatty acid inhibition of insulin secretion," Diabetes, vol. 53, no. 10, pp. 2610-2616, 2004.

[43] G. A. Martens, Y. Cai, S. Hinke, G. Stangé, M. van de Casteele, and D. Pipeleers, "Glucose suppresses superoxide generation in metabolically responsive pancreatic beta cells," The Journal of Biological Chemistry, vol. 280, no. 21, pp. 20389-20396, 2005.

[44] A. I. Oprescu, G. Bikopoulos, A. Naassan et al., "Free fatty acid-induced reduction in glucose-stimulated insulin secretion: evidence for a role of oxidative stress in vitro and in vivo," Diabetes, vol. 56, no. 12, pp. 2927-2937, 2007.

[45] J. W. Joseph, V. Koshkin, M. C. Saleh et al., "Free fatty acidinduced beta-cell defects are dependent on uncoupling protein 2 expression," The Journal of Biological Chemistry, vol. 279, no. 49, pp. 51049-51056, 2004.

[46] J. Fu, C. G. Woods, E. Yehuda-Shnaidman et al., "Low-level arsenic impairs glucose-stimulated insulin secretion in pancreatic beta cells: involvement of cellular adaptive response to oxidative stress," Environmental Health Perspectives, vol. 118, no. 6, pp. 864-870, 2010.

[47] J. P. Deglasse, L. P. Roma, D. Pastor-Flores, P. Gilon, T. P. Dick, and J. C. Jonas, "Glucose acutely reduces cytosolic and mitochondrial $\mathrm{H}_{2} \mathrm{O}_{2}$ in rat pancreatic beta cells," Antioxidants \& Redox Signaling, vol. 30, pp. 297-313, 2018.

[48] A. Neal, A. Rountree, K. Kernan et al., "Real-time imaging of intracellular hydrogen peroxide in pancreatic islets," The Biochemical Journal, vol. 473, no. 23, pp. 4443-4456, 2016. 
[49] C.-G. Li, C.-L. Ni, M. Yang et al., "Honokiol protects pancreatic $\beta$ cell against high glucose and intermittent hypoxiainduced injury by activating Nrf2/ARE pathway in vitro and in vivo," Biomedicine \& Pharmacotherapy, vol. 97, pp. 12291237, 2018.

[50] Y. Yagishita, T. Fukutomi, A. Sugawara et al., "Nrf2 protects pancreatic $\beta$-cells from oxidative and nitrosative stress in diabetic model mice," Diabetes, vol. 63, no. 2, pp. 605-618, 2014. 


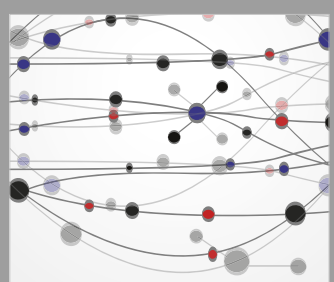

The Scientific World Journal
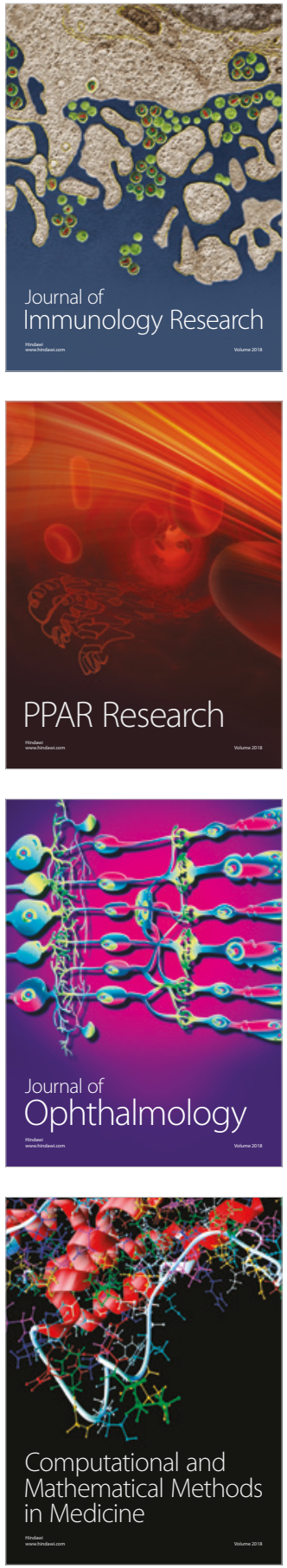

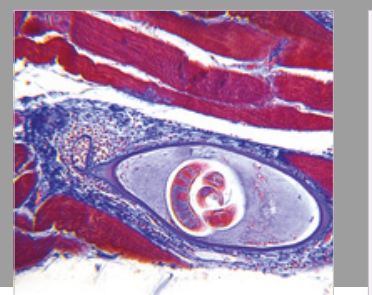

Gastroenterology Research and Practice

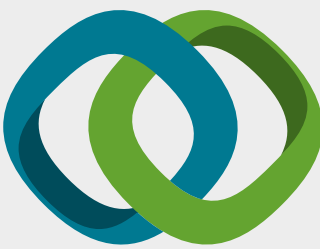

\section{Hindawi}

Submit your manuscripts at

www.hindawi.com
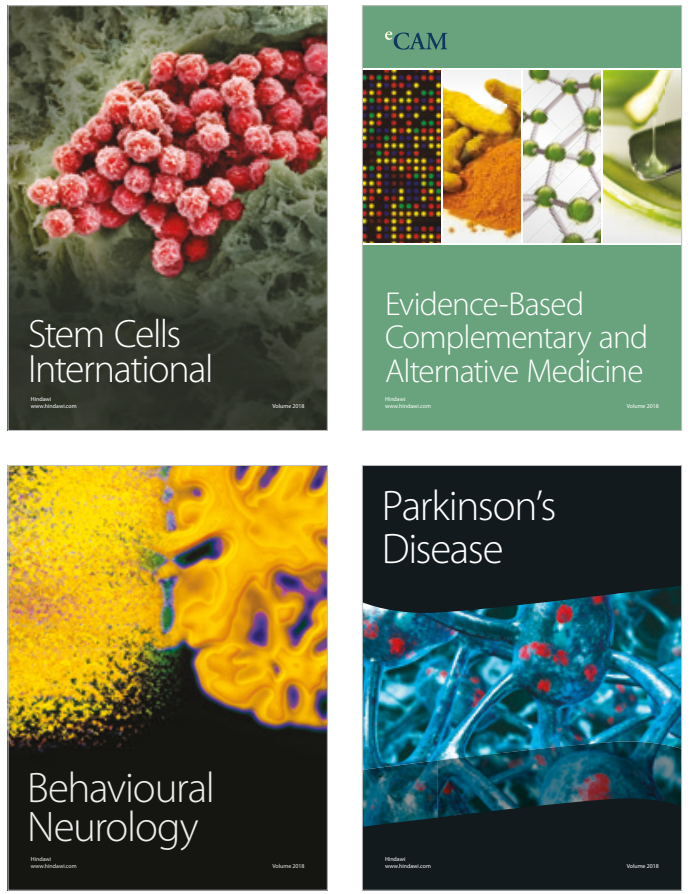

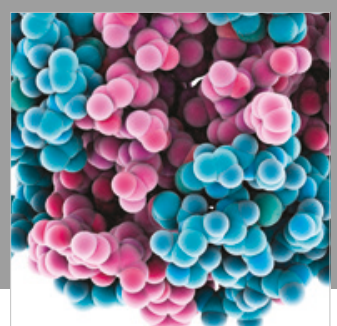

ournal of

Diabetes Research

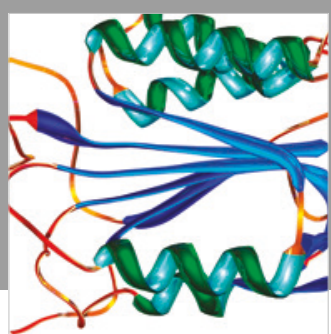

Disease Markers
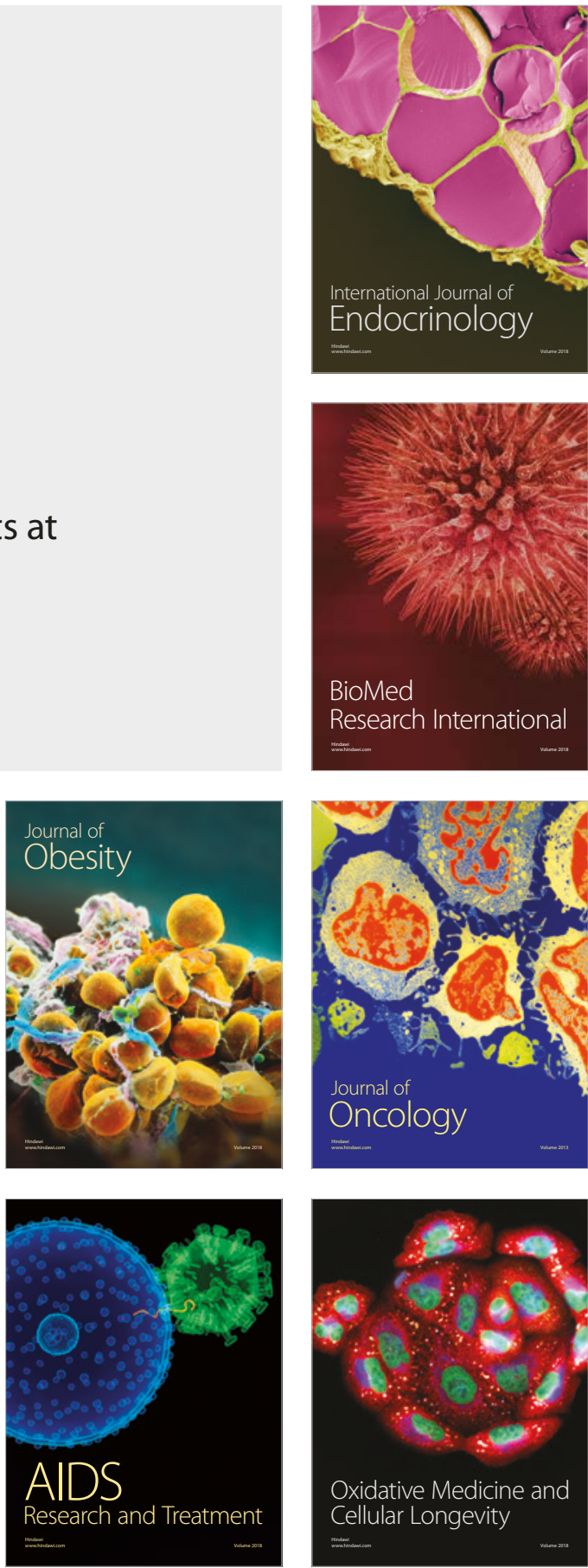